\title{
NR2A at CA1 Synapses Is Obligatory for the Susceptibility of Hippocampal Plasticity to Sleep Loss
}

\author{
Fabio Longordo, ${ }^{1}$ Caroline Kopp, ${ }^{2}$ Masayoshi Mishina, ${ }^{3}$ Rafael Luján, ${ }^{4}$ and Anita Lüthi ${ }^{1}$ \\ ${ }^{1}$ Department of Cell Biology and Morphology, University of Lausanne, CH-1005 Lausanne, Switzerland, ${ }^{2}$ Biozentrum, University of Basel, CH-4009 Basel, \\ Switzerland, ${ }^{3}$ Department of Molecular Neurobiology and Pharmacology, Graduate School of Medicine, The University of Tokyo, 113-0033 Tokyo, Japan, \\ and ${ }^{4}$ Departamento de Ciencias Medicas, Facultad de Medicina, Universidad de Castilla-La Mancha, 02006 Albacete, Spain
}

\begin{abstract}
A loss in the necessary amount of sleep alters expression of genes and proteins implicated in brain plasticity, but key proteins that render neuronal circuits sensitive to sleep disturbance are unknown. We show that mild $(4-6 \mathrm{~h})$ sleep deprivation (SD) selectively augmented the number of NR2A subunits of NMDA receptors on postsynaptic densities of adult mouse CA1 synapses. The greater synaptic NR2A content facilitated induction of CA3-CA1 long-term depression in the theta frequency stimulation range and augmented the synaptic modification threshold. NR2A-knock-out mice maintained behavioral response to SD, including compensatory increase in postdeprivation resting time, but hippocampal synaptic plasticity was insensitive to sleep loss. After SD, the balance between synaptically activated and slowly recruited NMDA receptor pools during temporal summation was disrupted. Together, these results indicate that NR2A is obligatory for the consequences of sleep loss on hippocampal synaptic plasticity. These findings could advance pharmacological strategies aiming to sustain hippocampal function during sleep restriction.
\end{abstract}

\section{Introduction}

Sleep facilitates plasticity of neuronal circuits that underlie development, learning, and memory (Walker and Stickgold, 2004; Dang-Vu et al., 2006). Experience-dependent plasticity of neuronal assemblies exposed to novel environmental and sensory stimuli is consolidated during subsequent sleep (Frank et al., 2001; Miyamoto and Hensch, 2003; Hennevin et al., 2007). Sleep also participates in homeostasis of synaptic strength (Vyazovskiy et al., 2008) and is accompanied by differential expression of genes and proteins involved in synaptic plasticity (Cirelli, 2006; Vyazovskiy et al., 2008).

Despite this recent progress, key molecules rendering neuronal circuits sensitive to sleep are unknown. Sleep deprivation (SD) is a suitable approach to assess candidate factors in neuronal tissue subject to enhanced sleep pressure (Cirelli, 2006; Longordo et al., 2009). A prominent SD-sensitive target is the glutamatergic

\footnotetext{
Received March 11, 2009; revised May 26, 2009; accepted June 11, 2009.

This work was supported by grants from the Swiss National Science Foundation to A.L. (No.3100A0-116006) and from the Consejería de Educación y Ciencia, Junta de Comunidades de Castilla-La Mancha (PAl08-0174-6967) to R.L. A.L. was supported by the Prof. Dr. Max Cloetta Foundation. The monoclonal anti-NR2B glutamate receptor antibody (NeuroMab clone N59/20) was obtained from the University of California, Davis/National Institutes of Health (NIH) NeuroMab Facility, supported by NIH Grant U24NS050606 and maintained by the Department of Neurobiology, Physiology and Behavior, College of Biological Sciences, University of California, Davis (Davis, CA). We thank Dr. Delpire for making the NR2A-knock-out mice available to us. We are indebted to Prof. G. K. Popescu for providing us with the reaction rate models of NR2A- and NR2B-NMDA receptor subtypes. The constructive input of Profs. L. Acsády, M. Scanziani, and K. Vogt in the course of the experiments is greatly appreciated. We thank Prof. U. Gerber and Drs. S. Astori and A. Scimemi for critical reading of this manuscript. Dr. Y. Auberson (Novartis, Basel) kindly provided us with the NVP-AAM077. CP-101,606 was made available through Pfizer (Groton, CT). We thank C. Haeberli for excellent technical assistance.

The authors declare no conflict of interest.

Correspondence should be addressed to Anita Lüthi, Department of Cell Biology and Morphology, University of Lausanne, Rue du Bugnon 9, CH-1005 Lausanne, Switzerland. E-mail: anita.luthi@unil.ch.

DOI:10.1523/JNEUROSCI.1215-09.2009

Copyright $\odot 2009$ Society for Neuroscience $\quad 0270-6474 / 09 / 299026-16 \$ 15.00 / 0$
}

NMDA receptor (NMDAR), important for the induction of many forms of synaptic plasticity (Malenka and Bear, 2004). Prolonged SD (24-72 h) altered cytosolic levels of the NMDAR subunits NR1 and NR2A in whole hippocampus preparations (Chen et al., 2006; McDermott et al., 2006). A short (4-6 h) SD resulted in selectively enhanced membrane levels of the NMDAR subunit NR2A in purified hippocampal synaptosomes (Kopp et al., $2006)$. Periods of spontaneous wakefulness in rats ( $>75 \%$ of the last $6 \mathrm{~h}$ ) were accompanied by elevated NR2A protein in hippocampal and, to a weaker extent, in cortical tissue preparations enriched in synaptic proteins (Vyazovskiy et al., 2008). However, whether enriched NR2A expression levels underlie the susceptibility of hippocampal and cortical circuits to sleep loss remains unknown (Graves et al., 2003; Vyazovskiy et al., 2008).

The NR2A subunit is an attractive candidate for a mechanistic link between sleep loss and neuronal plasticity. Augmented expression of NR2A is induced by both spontaneous and enforced waking, and is reversible through $3 \mathrm{~h}$ of recovery sleep (Kopp et al., 2006; Vyazovskiy et al., 2008). Moreover, various studies report that SD alters NMDAR-dependent forms of synaptic plasticity (Campbell et al., 2002; Davis et al., 2003; McDermott et al., 2003; Kopp et al., 2006) and hippocampus-dependent learning (Graves et al., 2003). Finally, NR2A subunit content sets kinetic profiles and signaling characteristics of NMDAR-mediated currents (Cull-Candy and Leszkiewicz, 2004) proposed to be important for bidirectional synaptic plasticity (Yashiro and Philpot, 2008).

Here, we identify an obligatory role for NR2A-containing NMDARs (NR2A-NMDARs), localized on the spines of apical CA1 dendrites, in conveying the effect of sleep loss on CA1 synaptic plasticity. Genetic deletion of the NR2A subunit does not alter sleep-wake behavior and homeostatic response to SD, but it 
preserves hippocampal plasticity from the impact of sleep loss. As to NR2A's role, we show that the increased synaptic NR2A content after sleep loss distinctly affects the contribution of synaptic and more slowly recruited NMDAR pools to temporal summation during plasticity-induction protocols. This study establishes a mechanistic link between a molecular correlate of sleep loss and its impact on system-relevant neuronal functions.

\section{Materials and Methods}

Animals. C57BL/6J mice were generated from breeding pairs obtained from RCC Laboratory Animal Services. The NR2A-knock-out (NR2A KO) line (Sakimura et al., 1995) was repeatedly backcrossed into the C57BL/6J line from our provider. Adult postnatal day 56-70 (P56-P70) wild-type (WT) C57BL/6J and NR2A KO mice were kept in standard Macrolon cages and maintained on a $12 \mathrm{~h}$ light/dark cycle (light from 7:00 A.M. to 7:00 P.M.) with food and water provided ad libitum. Mice were genotyped by PCR. All experiments were performed in agreement with the guidelines of the Veterinary Institutes of the Canton Basel-Stadt and of the Canton de Vaud.

Behavioral monitoring and SD. Three to seven days before being used, all animals were transferred to a testing room controlled for temperature $\left(21.7-25.2^{\circ} \mathrm{C}\right)$, relative humidity $(47-64 \%)$, and noise $(\sim 45-50 \mathrm{dBA}$ during the light phase). Subgroups of mice were regularly monitored (4-8 animals/month) for their sleep-wake behavior via tracking spontaneous locomotor activity (distance traveled per unit of recording time) using Ethovision 3.0 (Noldus Information Technology). As previously reported (Kapfhamer et al., 2002; Kopp et al., 2006), sleeping time approximated by the resting time (percentage of recording time during which the mouse activity equals $0 \mathrm{~mm}$ per second) was measured. All WT animals used in this study showed a distribution of resting and active behavior that was well entrained to the light-dark cycle and typical for an undisturbed $24 \mathrm{~h}$ cycle (Kopp et al., 2006).

SD was essentially performed as previously described in detail (Kopp et al., 2006) and was halted when mice remained in a sleeping position for $>5$ min (i.e., after $4.5 \pm 0.1 \mathrm{~h} ; n=58$ mice in total). Control undisturbed mice ( $n=92$ mice in total) were left totally undisturbed and were killed at the same time of day as the sleep-deprived animals (between 11:30 A.M. and 01:30 P.M.).

For behavioral analysis in NR2A KO mice, a subgroup of P56-P70 littermate WT $(n=6)$ and NR2A KO $(n=9)$ animals was used. For each session, 2-4 animals were monitored in the testing room, with at least one WT animal included. Baseline locomotor activity was tracked during three consecutive undisturbed light-dark cycles $(72 \mathrm{~h})$. The levels of activity and resting time of all the animals were quantified during SD and the following recovery period.

Electron microscopy. For each experimental group (WT, NR2A KO, $\mathrm{SD}), n=3$ animals were used. Mice were kept under deep anesthesia with isoflurane and perfused through the ascending aorta with $0.9 \%$ saline for 1-2 min, followed by freshly prepared ice-cold fixative solution containing $4 \%$ paraformaldehyde, $0.05 \%$ glutaraldehyde and $15 \%$ saturated picric acid solution made up in $0.1 \mathrm{~m}$ phosphate buffer ( $\mathrm{PB} ; \mathrm{pH} 7.2-7.4$ ). Each animal was perfused with $\sim 150 \mathrm{ml}$ of fixative solution. After perfusion, brains were removed from the skull and immersed in ice-cold PB for $2 \mathrm{~h}$. Brains were then stored in ice-cold PB containing $1 \mathrm{M}$ sucrose and $0.05 \% \mathrm{NaN}_{3}$ until sections were prepared. Blocks from three hippocampi were washed in $0.1 \mathrm{M}$ PB for $2 \mathrm{~h}$. Sections of the hippocampus were cut at $500 \mu \mathrm{m}$, incubated in $1 \mathrm{M}$ sucrose/PBS solution overnight, slammed onto copper blocks cooled in liquid nitrogen, and embedded in Lowicryl HM 20 (TAAB Laboratories) after freeze substitution with methanol. Ultrathin sections $(70-90 \mathrm{~nm})$ from three Lowicryl-embedded blocks were incubated for $45 \mathrm{~min}$ on pioloform-coated nickel grids with drops of blocking solution consisting of $2 \%$ albumin in $0.05 \mathrm{M} \mathrm{TBS}, 0.9 \% \mathrm{NaCl}$ and $0.03 \%$ Triton $\mathrm{X}-100$. The grids were transferred to solutions of NR2A (Millipore Bioscience Research Reagents) or NR2B [University of California, Davis (UC Davis)/National Institutes of Health (NIH) NeuroMab Facility, Davis, CA] antibodies at a final protein concentration of $10 \mu \mathrm{g} / \mathrm{ml}$ diluted in blocking solution overnight at room temperature.

After several washes in TBS, grids were incubated for $2 \mathrm{~h}$ in drops of goat anti-mouse $\operatorname{IgG}$ conjugated to $10 \mathrm{~nm}$-colloidal gold particles (BioCell International), each diluted 1:80 in a $0.05 \mathrm{~m}$ TBS solution containing $2 \%$ normal human serum and $0.5 \%$ polyethylene glycol. Grids were then washed in TBS for $30 \mathrm{~min}$ and counterstained for electron microscopy (EM) with saturated aqueous uranyl acetate and lead citrate. Ultrastructural analyses were performed in a Jeol-1010 electron microscope. Electron photomicrographs were captured with CCD camera (Mega View III, Soft Imaging System). Digitized electron images were then modified for brightness and contrast by using Adobe PhotoShop CS1 to optimize them for printing.

To establish the relative abundance of NR2A and NR2B immunoreactivity in the different experimental groups, quantification of immunolabeling was performed in the distal part of the stratum radiatum from 80 $\mathrm{nm}$ ultrathin sections. For each of three animals, three samples of tissue were obtained (nine total blocks). Areas were randomly chosen and were digitally captured at a magnification of 50,000 $\times$. Only synapses made by axon terminals with pyramidal cell spines were included in the analysis. Nonlabeled synapses were not considered. Immunoparticles were counted within the anatomically defined synaptic junctions. The length of the postsynaptic density was measured on ultrathin sections and the number of immunoparticles per postsynaptic density was counted. This procedure was shown previously to provide reliable estimates of NMDAR subunit density (Lin et al., 2008). Finally, the density of NR2A or NR2B along the postsynaptic densities of dendritic spines of pyramidal cells, measured as number of immunoparticles per micrometer, was calculated in control conditions, after SD and in NR2A KO mice. Before carrying out statistical tests, data were assessed for their normal distribution, which was found to be the case for particle densities of both control and sleep-deprived animals ( $p=0.409)$. Background staining of immunoparticles was measured over mitochondria and capillaries over a 2000 $\mu \mathrm{m}^{2}$ area, and amounted to $0.04 \pm 0.02 \mathrm{particles} / \mu \mathrm{m}^{2}$ in WT mice and to $0.04 \pm 0.01$ particles $/ \mu \mathrm{m}^{2}$ in NR2A KO mice.

Electrophysiological recordings. Parasagittal slices (300-400 $\mu \mathrm{m})$ were prepared according to standard procedures (Kopp et al., 2006). A cut was applied between CA3 and CA1 to prevent epileptic discharges.

For extracellular recordings, slices $(400 \mu \mathrm{m})$ were placed in an interface-style recording chamber at $33.0 \pm 0.5^{\circ} \mathrm{C}$ and continuously perfused with standard artificial CSF (ACSF) (in mM): $131 \mathrm{NaCl} ; 2.5 \mathrm{KCl}$; $1.25 \mathrm{NaH}_{2} \mathrm{PO}_{4} ; 1.2 \mathrm{MgCl}_{2} ; 2 \mathrm{CaCl}_{2} ; 26 \mathrm{NaHCO}_{3}, 20$ dextrose, $1.7 \mathrm{~L}(+)$ ascorbic acid supplemented with picrotoxin $(25-50 \mu \mathrm{M})$ and bubbled with $95 \% / 5 \% \mathrm{O}_{2} / \mathrm{CO}_{2}$. Field EPSPs (fEPSPs) were evoked by recruiting Schaffer collateral inputs with $100 \mu$ s pulses delivered through bipolar stimulation and recorded with a glass pipette (2-3 M $\Omega$ ) filled with ACSF and positioned in the CA1 stratum radiatum. Stimulation intensity was adjusted to $\sim 50 \%$ of the maximal response before population spikes started to appear, requiring stimulation intensities of 20-60 $\mu \mathrm{A}$. Average fEPSP slopes were $-362 \pm 18 \mu \mathrm{V} / \mathrm{ms}$ ( $n=77$ slices in control mice) and $-382 \pm 21 \mu \mathrm{V} / \mathrm{ms}(n=71$ slices in sleep-deprived mice). The signals were amplified 1000 times and filtered between 10 and $3000 \mathrm{~Hz}$ (Differential Amplifier DP301; Warner Instruments) before being digitally acquired at $10 \mathrm{kHz}$ (Clampex 9.2; Molecular Devices). Analysis was completed using Clampfit 9.2. Before inducing plasticity, a 10 min baseline of fEPSPs at $0.05 \mathrm{~Hz}$ was recorded that fulfilled the following stability criteria: standard deviation $<5 \%$, slope of linear fitting $< \pm 0.1 \% / \mathrm{min}$. Conditioning protocols of 900 pulses delivered at $5 \mathrm{~Hz}$ or $10 \mathrm{~Hz}$ were applied, followed by $30 \mathrm{~min}$ postconditioning at a stimulation frequency of $0.05 \mathrm{~Hz}$. In NR2A KO mice, bidirectional synaptic plasticity was assessed by using $1 \mathrm{~Hz}$ low-frequency stimulation $(900$ pulses at $1 \mathrm{~Hz}$ ) and $100 \mathrm{~Hz}$ high-frequency stimulation (two $1 \mathrm{~s}$ pulses at $100 \mathrm{~Hz}$ separated by $30 \mathrm{~s}$ ). When testing the effects of NMDAR antagonists on synaptic plasticity, experiments in drug-free conditions (ACSF) were always performed interleaved to test experiments, in which slices were preincubated with a single antagonist for at least $1 \mathrm{~h}$. Effects of the drugs were analyzed and plotted with respect to the interleaved ACSF experiments. Synaptic strength of the postsynaptic response was assessed by the $10-$ $90 \%$ slope of the fEPSP and normalized to the corresponding mean baseline value. Long-term plasticity was assessed during the last $10 \mathrm{~min}$ of $30 \mathrm{~min}$ of postconditioning recordings. In individual experiments, the 
criterion for long-term depression (LTD) and long-term potentiation (LTP) induction was set at $\geq 10 \%$ of absolute change from baseline.

For whole-cell voltage-clamp experiments, slices $(300 \mu \mathrm{m})$ were transferred to a storage chamber filled with ACSF and maintained at $35^{\circ} \mathrm{C}$ for the first $30 \mathrm{~min}$ and then allowed to cool to room temperature $\left(21-22^{\circ} \mathrm{C}\right)$. For recordings, slices were transferred to a submerged recording chamber and maintained at nearphysiological temperature $\left(32.5-33.5^{\circ} \mathrm{C}\right)$ in ACSF. Patch pipettes (2.5-3.5 M $\Omega$ ) were pulled from borosilicate glass (TW150F-4; World Precision Instruments) and filled with the following (in mM): 127 cesium gluconate, 10 HEPES, 2 cesium BAPTA, $6 \mathrm{MgCl}_{2}, 2 \mathrm{Mg}$-ATP, and 10 phosphocreatine, adjusted to $\mathrm{pH} 7.25-7.28$ with gluconic acid and to 290-295 mOsm. MgGTP (0.2 mM) and QX-314 (1 mM) were freshly added daily, and the solution was filtered and maintained on ice. This solution yielded a liquid junction potential of $-10 \mathrm{mV}$ (Kopp et al., 2006), which was not compensated. Whole-cell recordings were obtained under visual control, using near-infrared differential interference contrast microscopy (BX51WI; Olympus). Voltage-clamp recordings were obtained using an Axopatch 200B amplifier (Molecular Devices), filtered at $2 \mathrm{kHz}$, and acquired at $10 \mathrm{kHz}$ using pClamp 9.2 software. Analysis was completed using Clampfit 9.2. After obtaining whole-cell access, synaptic currents were evoked every $20 \mathrm{~s}$ by brief current pulses delivered via a bipolar stimulation electrode placed in the CA1 stratum radiatum. Series resistances $(<20 \mathrm{M} \Omega)$ were constantly monitored throughout the experiments and changes $>20 \%$ were not accepted.

To study pharmacology of NMDAR-mediated synaptic responses, NMDAR-mediated EPSCs (NMDAR-EPSCs) were recorded at a holding potential of -35 to $-30 \mathrm{mV}$, while stimulating Schaffer collaterals at $0.033 \mathrm{~Hz}$, in the presence of picrotoxin $(100 \mu \mathrm{M})$, glycine $(1 \mu \mathrm{M})$ and the AMPA/kainate receptor antagonist DNQX $(40 \mu \mathrm{M})$ or NBQX $(10 \mu \mathrm{M})$. After obtaining a stable baseline of 15 min (30 sweeps), the NR2BNMDAR selective antagonist CP-101,606 (CP; $10 \mu \mathrm{M})$ or the NR2ANMDAR preferential antagonist NVP-AAM077 (NVP; 50 nM) were bath-applied for at least $20 \mathrm{~min}$. At the end of each experiment, the response was blocked by D,L-APV $(100 \mu \mathrm{M})$. Evoked currents, from which the responses in D,L-APV were digitally subtracted, were measured at their peak and normalized to the corresponding mean baseline amplitude. Antagonist effects were quantified as percentage of baseline responses in the last $10 \mathrm{~min}$ of recordings. A major portion of the pharmacological experiments was performed blind to genotype.

Temporal summation of NMDAR-EPSCs in response to $5 \mathrm{~Hz}$ stimulation was quantified at a holding potential of $+40 \mathrm{mV}$. Stimulation of Schaffer collaterals was adjusted to evoke NMDAR-EPSCs in the range of $50-150 \mathrm{pA}$, and average responses were comparable in the different experimental groups (WT, SD, and NR2A KO) (see Fig. 8 and legend), such that equivalent voltage-clamp control could be ensured (Diamond, 2001; Arnth-Jensen et al., 2002). Experiments from control and sleep-deprived animals were run in an interleaved manner. First, the stability of the NMDAR-mediated response was tested by using a single-pulse protocol, which consisted of three NMDAR-EPSCs elicited at $0.05 \mathrm{~Hz}$ at $+40 \mathrm{mV}$, followed by a silent period of 5 min during which the cell was held at $-55 /-50 \mathrm{mV}$. The stability of the reversal potential was also monitored by recording the NMDAR-EPSC at +10 and $+20 \mathrm{mV}$ before stimulation at $+40 \mathrm{mV}$. After obtaining a stable response for at least 3 successive single-pulse protocols, a stimulation train protocol was applied that consisted of 3 consecutive $5 \mathrm{~Hz}$ trains of 50 pulses at $25 \mathrm{~s}$ intervals. Unless otherwise noted, averaged NMDAR-mediated currents were normalized to the peak amplitude of the response induced by the first pulse. When the effects of NMDAR antagonists on temporally summated currents were studied, a first stimulation train protocol was elicited in ACSF. The cell was then repolarized to $-55 /-50 \mathrm{mV}$ during the bath application of the antagonist. After $15 \mathrm{~min}$ of drug application, NMDAR-EPSCs were recorded at $+10 \mathrm{mV},+20 \mathrm{mV}$, and $+40 \mathrm{mV}$ to check for the stability of the reversal potential and a stimulation train protocol in the presence of the antagonist was then applied. At the end of each experiment the current was blocked by application of the general antagonist D, L-APV $(100 \mu \mathrm{M})$.

AMPA receptor (AMPAR)-EPSCs were recorded at -60 to $-65 \mathrm{mV}$ in the presence of picrotoxin $(100 \mu \mathrm{M})$. For temporal summation of AMPAR-mediated currents, the stability of the AMPAR-EPSCs was tested by eliciting single pulse stimulation at $0.05 \mathrm{~Hz}$. After obtaining a stable response, the stimulation train protocol at $5 \mathrm{~Hz}$ was applied.

Calculation of the relative contributions of NR2A- and NR2B-NMDARs to the NMDAR-EPSCs and prediction of summed actions of NVP plus CP. Given the high selectivity of CP for NR2B-NMDARs (Köhr, 2006) and its low affinity for triheteromeric NR2A/NR2B-NMDARs (Chazot et al., 2002), we estimated the total contribution of diheteromeric NR2BNMDAR to an NMDAR-EPSC (NR2B ${ }_{\mathrm{WT}}$; expressed as a fraction of 1 ) by using the following equation: $\mathrm{NR}^{2} \mathrm{~B}_{\mathrm{WT}}=\left(f_{\mathrm{CP}_{-} \mathrm{WT}} / f_{\mathrm{CP} \_ \text {KO }}\right)$, where $f_{\mathrm{CP}_{\text {}} \text { WT }}$ and $f_{\mathrm{CP} \_ \text {KO }}$ represent the CP-sensitive components in WT and NR2A KO mice, respectively, normalized to the NMDAR-EPSC amplitudes during baseline recording $\left(I_{\mathrm{NMDA} \_W T}\right.$ and $I_{\mathrm{NMDA} \_ \text {KO}}$, respectively). Given the dominant expression of NR2A and NR2B subunit proteins at adult synapses in the hippocampus (Monyer et al., 1994), the remaining fraction $\left(\mathrm{NR} 2 \mathrm{~A}_{\mathrm{WT}}=1-\mathrm{NR} 2 \mathrm{~B}_{\mathrm{WT}}\right)$ is mediated by NR2Acontaining receptors (di- and triheteromers).

We then used the estimated relative contribution of NR2B- and NR2A-NMDARs to predict the NMDAR-mediated current sensitive to the application of $\mathrm{CP}+\mathrm{NVP}$ in combination $\left(I_{\mathrm{CP}+\mathrm{NVP}-\mathrm{WT}}\right)$ by using the following equation: $I_{\mathrm{CP}+\mathrm{NVP} \_\mathrm{WT}}=I_{\mathrm{NMDA} \_\mathrm{WT}}-\left[\left(I_{\mathrm{NMDA} \_\mathrm{WT}}{ }^{*}\right.\right.$ $\left.\left.\mathrm{NR} \mathrm{A}_{\mathrm{WT}}{ }^{*} 0.77\right)+\left(I_{\mathrm{NMDA} \_\mathrm{WT}}{ }^{*} \mathrm{NR} 2 \mathrm{~B}_{\mathrm{WT}}{ }^{*} f_{\mathrm{NVP} \_\mathrm{KO}}\right)\right]-\left[\left(I_{\mathrm{NMDA} \_\mathrm{WT}}{ }^{*}\right.\right.$ $\left.\left.\mathrm{NR}_{2} \mathrm{~B}_{\mathrm{WT}}\right) *\left(1-f_{\mathrm{NVP} \_\mathrm{KO}}\right)^{*} f_{\mathrm{CP}_{\mathrm{K}} \mathrm{KO}}\right]$, where $f_{\mathrm{NVP} \_ \text {KO }}$ is the fraction of NMDAR-EPSC blocked by NVP ( $50 \mathrm{nM})$ in NR2A KO mice and 0.77 is the fraction of pure recombinant NR2A-NMDARs blocked by 50 nM NVP (Berberich et al., 2005). The first term in the first square bracket represents 
A
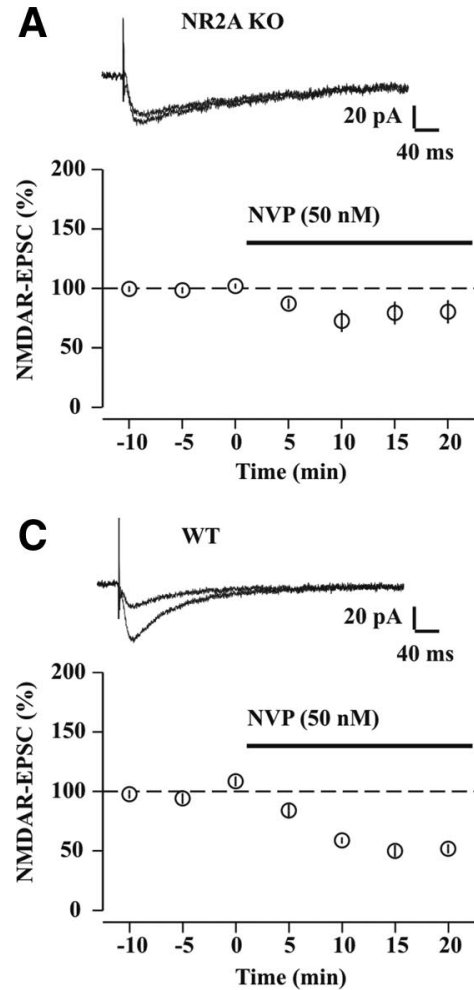

E
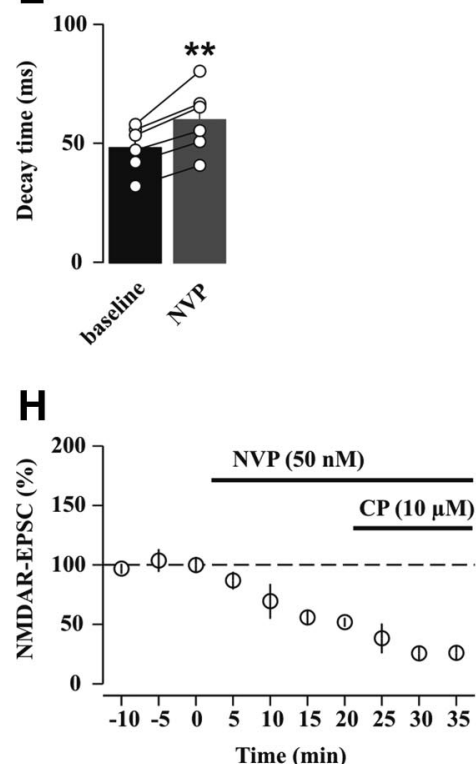
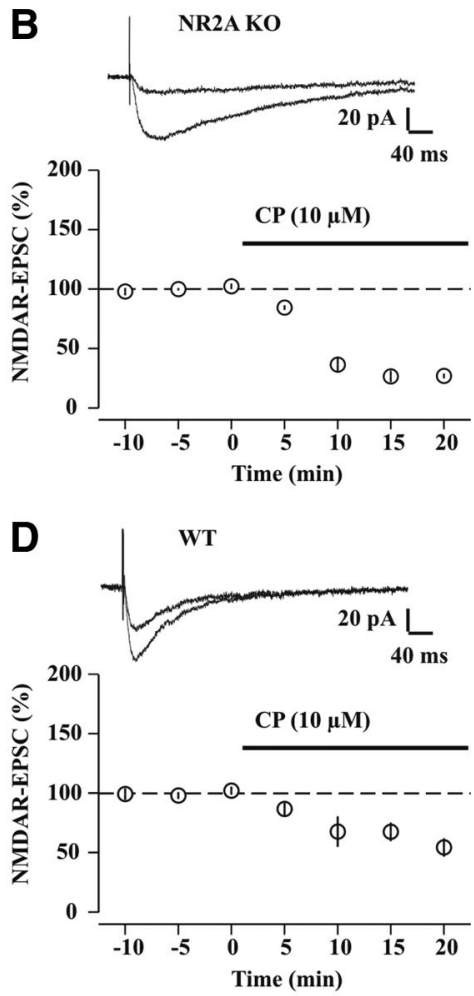

$\mathbf{F}$
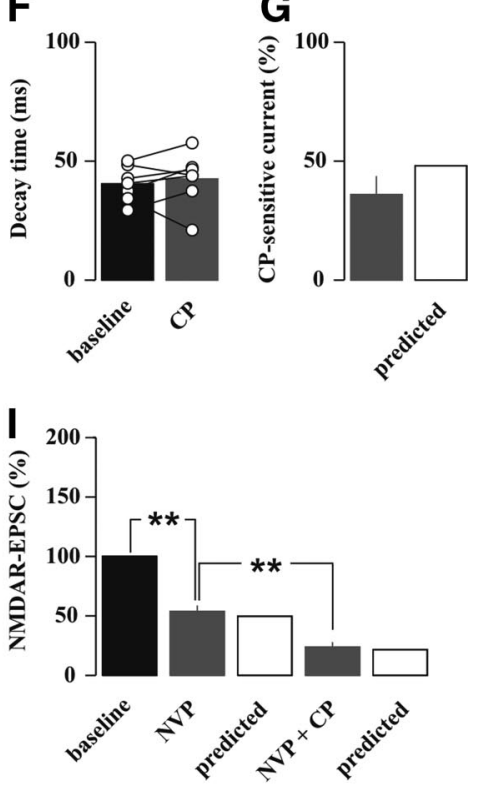

Figure 2. Effects of NVP $(50 \mathrm{~nm})$, a preferential NR2A-NMDAR antagonist, and CP $(10 \mu \mathrm{m})$, a selective NR2B-NMDAR antagonist, on synaptically evoked NMDAR-EPSCs at adult CA3-CA1 synapses. $\boldsymbol{A}, \boldsymbol{B}$, Time course of average NMDAR-EPSC amplitudes (percentage of baseline) before and during application of $50 \mathrm{~nm} \mathrm{NVP,}(\boldsymbol{A}, n=9, p=0.05$, paired $t$ test) or 10 $\mu \mathrm{M} C P,(B, n=6, p<0.0001$, paired $t$ test) in slices from NR2A K0 mice. For plots, data were binned at 5 min intervals. Averaged sample traces (mean of $10-30$ consecutive sweeps) are shown on top. $C, D$, Time course of average NMDAR-EPSC amplitudes (percentage of baseline) before and during application of $50 \mathrm{~nm} \mathrm{NVP}(C, n=6, p<0.0005$, paired $t$ test) or 10 $\mu \mathrm{m} C P(\boldsymbol{D} ; n=7, p<0.005$, paired $t$ test $)$ in slices from WT mice. Averaged sample traces are shown on top. $\boldsymbol{E}, \boldsymbol{F}$, Effect of $50 \mathrm{~nm} \operatorname{NVP}(\boldsymbol{E})$ and $10 \mu \mathrm{M} C P(\boldsymbol{F})$ on decay time of NMDAR-EPSCs in slices from WT mice. Bars represent mean decay time values, and vertical scatter plots show individual experiments. ${ }^{* *} p<0.005$ (paired $t$ test). $G$, Amplitude of the (P-sensitive EPSC (percentage of baseline) in slices from WT mice (gray bar) and predicted amplitude of the NR2B-NMDAR-mediated EPSC (white bar). $\boldsymbol{H}$, Time course of average NMDAR-EPSC amplitudes (percentage of baseline) before and during application of $50 \mathrm{~nm}$ NVP alone and in combination with $10 \mu \mathrm{M} C P$ in slices from WT mice $(n=5)$. $I$, Histograms summarizing the effects of NMDAR antagonists. White bars indicate the predicted actions of NVP alone and in combination with CP (see Materials and Methods). ${ }^{* *} p<0.001$ (paired $t$ test).

the estimated current mediated by NR2Acontaining receptors $\left(I_{\mathrm{NMDA}} \mathrm{wT}^{*} \mathrm{NR} 2 \mathrm{~A}_{\mathrm{WT}}\right)$ that is blocked by $50 \mathrm{nM}$ NVP by a factor of 0.77. The second term represents the estimated current mediated by NR2B-containing receptors $\left(I_{\mathrm{NMDA} \_ \text {WT }}{ }^{*} \mathrm{NR} 2 \mathrm{~B}_{\mathrm{WT}}\right)$ that is blocked by $\operatorname{NVP}\left(f_{\text {NVP_KO }}\right)$. The terms in the second square bracket represent the estimated residual current mediated by NR2B-containing receptors after the application of NVP $\left[\left(I_{\mathrm{NMDA}} \mathrm{wT}^{*}\right.\right.$ $\left.\left.\mathrm{NR} 2 \mathrm{~B}_{\mathrm{WT}}\right)^{*}\left(1-f_{\mathrm{NVP} \text { KO }}\right)\right]$ that is blocked by the application of $10 \mu \mathrm{M} \mathrm{CP}$ by a factor of $f_{\mathrm{CP} \text { KO }}$.

Data analysis. Kinetic properties of NMDAR-mediated currents evoked by a single pulse or at the end of a $5 \mathrm{~Hz}$ train of stimulation were studied as additional indicators of NMDAR subtype dominance in the synaptic response. To simplify the comparison across conditions, a single weighted decay measure (referred to in the text as decay time) was calculated by normalizing the charge transfer with the peak amplitude of the NMDAR-mediated currents (Arnth-Jensen et al., 2002; Lozovaya et al., 2004; Bellone and Nicoll, 2007). Charge transfer during the decay of the current was calculated from the integral of the current between the time of the EPSC peak and the time at which the current had returned to baseline. Datasets showed comparable low average series resistances (typically $<15 \mathrm{M} \Omega$ in cells used for kinetics analysis) and similar EPSC sizes (see above) minimizing possible voltage-clamp artifacts that could have affected the kinetics of NMDAR-mediated currents. The effect of SD on the decay kinetics of NMDAR-mediated currents at the end of $5 \mathrm{~Hz}$ stimulation trains was confirmed by fitting decay curves with a biexponential function and then calculating the weighted time constants (Rumbaugh and Vicini, 1999) (data not shown).

When studying the properties of temporally summated NMDAR-mediated currents, persistent current components were quantified by measuring the amplitude of the current just preceding each stimulation artifact, whereas phasic current components were quantified by measuring NMDAR-EPSCs peak amplitude relative to the preceding baseline.

Linear summation of NMDAR-EPSCs. A subset of representative experiments from WT $(n=$ $8)$ and NR2A KO $(n=8)$ mice were chosen. For each dataset, the decay of experimentally measured NMDAR-EPSCs was fitted with a biexponential function $I(t)=A_{\mathrm{f}} \exp \left(-t / \tau_{\mathrm{f}}\right)+$ $A_{\mathrm{s}} \exp \left(-t / \tau_{\mathrm{s}}\right)$, over a $800 \mathrm{~ms}$ window from the peak. $A_{\mathrm{f}}$ and $A_{\mathrm{s}}$ are the amplitudes of the fast and slow components, and $\tau_{\mathrm{f}}$ and $\tau_{\mathrm{s}}$ are the respective time constants. The stimulus artifact and the rising component of the NMDAR-EPSCs were substituted with a $4 \mathrm{~ms}$ steady value equal to 0 . NMDAR-EPSCs after the first pulse were scaled according to the phasic NMDAR-EPSC amplitudes. Fifty consecutive NMDAR-EPSCs were summated at $5 \mathrm{~Hz}$. The properties of simulated NMDAR-mediated currents were analyzed as the experimental data.

Computational simulations. Reaction rate models of NMDAR subtypes were derived from published work (Popescu, 2005) and 
from unpublished data (S. A. Amico-Ruvio and G. K. Popescu). Currents were simulated with ChanneLab version 2 (Synaptosoft). For simulating repeated glutamate release, the Stimulus Feature of ChanneLab was used to create repeated glutamate transients at $5 \mathrm{~Hz}$, with an instantaneous rise and a decay time constant of $1.2 \mathrm{~ms}$ according to Clements et al., 1992. The amplitude of these pulses was determined by fitting the AMPAR model by Diamond and Jahr (1997), such that the experimentally measured AMPAR-mediated currents during repeated stimulation (see Fig. 9) were closely reproduced. These showed a slight facilitation, which could be reproduced by using glutamate concentrations of $0.55 \mathrm{~mm}$ for the first pulse, 0.825 $\mathrm{mm}$ for pulses $2-15$ and $0.7 \mathrm{~mm}$ for pulses 16-20 (data not shown).

Drugs and chemicals. Picrotoxin, D,L-APV, DNQX, and NBQX were purchased from Tocris Cookson; D-AA and standard salts were from Sigma-Aldrich. CP-101,606 was from Pfizer Pharmaceuticals and NVPAAM077 was from Novartis Pharma. For NR2A, a monoclonal antibody was obtained from Millipore Bioscience Research Reagents. For NR2B, a monoclonal antibody was obtained from UC Davis/NIH NeuroMab Facility (Davis, CA).

Statistics. Values are given in mean \pm SEM. Statistics were done using ANOVA and $t$ tests (two-tailed paired and unpaired for within and between group comparisons, respectively) using SPSS version 14.0. Chi squared ( $\chi^{2}$ test) and Kolmogorov-Smirnov tests were also used when indicated. Significance was set at $p<0.05$.

\section{Results}

\section{Electron microscopy reveals equal} amounts of NR2A and NR2B at control CA3-CA1 synapses and increased NR2A levels after SD

The relative amounts of NR2A and NR2B proteins, the predominant NR2 subunits of NMDARs in the adult hippocampus, were first probed via EM using postembedding immunogold and quantitative approaches in adult WT mice with a well entrained sleep-wake cycle (see Materials and Methods). Immunogold labeling for either NR2A or NR2B revealed almost exclusive labeling of the postsynaptic densities of dendritic spines (Fig. 1A, B), whereas extrasynaptic compartments contained very low levels of immunoreactivity. The density of gold particles, counted over the anatomically defined postsynaptic density of asymmetric synapses in CA1 stratum radiatum, was comparable for NR2A and NR2B antibodies (NR2A: $11.652 \pm 7.143 / \mu \mathrm{m}, n=70$ synapses with 150 particles; NR2B: $12.404 \pm 7.692 / \mu \mathrm{m}, n=70$ synapses with 155 particles), and similar to densities reported in adult rat tissue (Racca et al., 2000). At CA1 synapses from NR2A KO animals, no labeling for NR2A could be found ( $n=70$ synapses).

Analysis of CA1 synapses derived from mice that had undergone a mild SD (see Materials and Methods) (Kopp et al., 2006) revealed 1.6-fold greater levels of NR2A at synaptic sites $(18.750 \pm 14.286 / \mu \mathrm{m}, n=70$ synapses with 248 gold particles, $p<0.001$ compared with synapses from control mice) (Fig. $1 C$,
$D)$. In contrast, NR2B immunogold density was not affected by SD $(11.438 \pm 8.333 / \mu \mathrm{m}, n=70$ synapses with $n=154$ gold particles, $p>0.05$ ) (Fig. $1 E$ ). Furthermore, average lengths of postsynaptic densities were similar (control: $0.179 \pm 0.032 \mu \mathrm{m}$; SD: $0.180 \pm 0.029 \mu \mathrm{m}, p>0.05$ ), excluding the possibility that enlarged synapse size contributed to increased receptor numbers. Therefore, synapses from undisturbed mice contained equal levels of NR2A and NR2B protein, whereas SD selectively augmented the number of NR2A subunits at synaptic sites.

\section{NR2A- and NR2B-NMDARs equally contribute to generate NMDAR-EPSCs at adult CA3-CA1 synapses}

To assess the consequences of the SD-induced enhancement of NR2A subunit protein on CA3 to CA1 synaptic transmission and plasticity, we started by evaluating the efficacy of subtype-specific NMDAR antagonists in acute slices prepared from WT and NR2A KO mice kept under undisturbed housing conditions (see Materials and Methods). CP (10 $\mu \mathrm{M})$, a well established NR2B- 
A
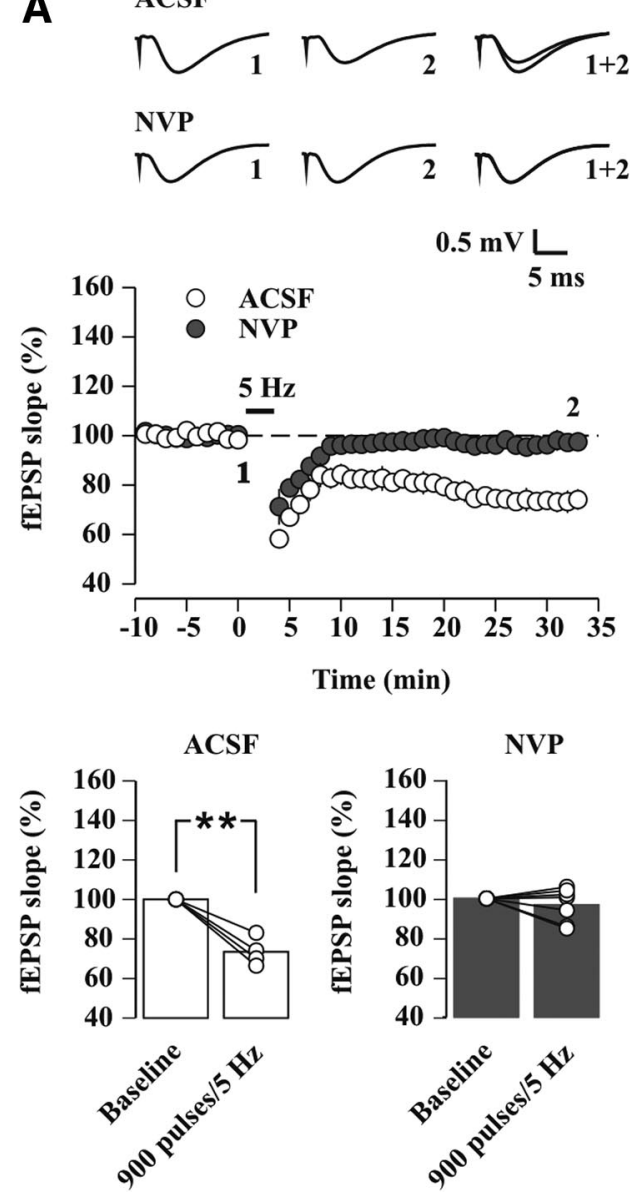

B

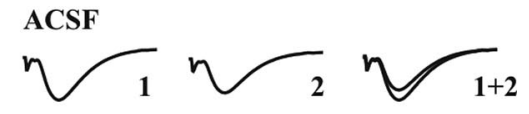

CP
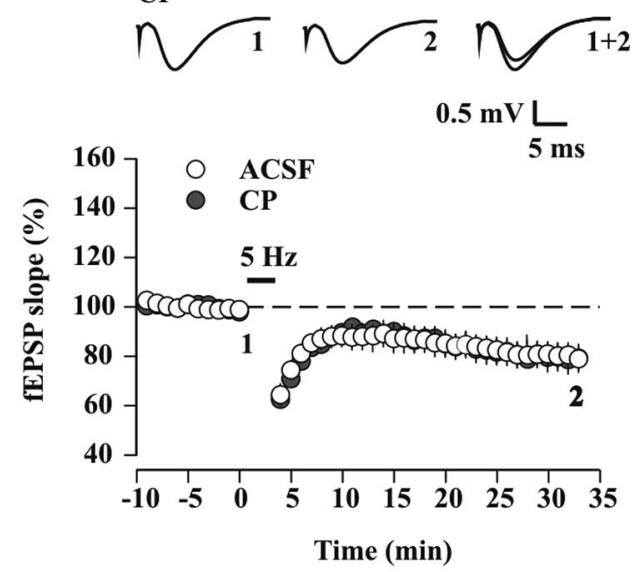

ACSF
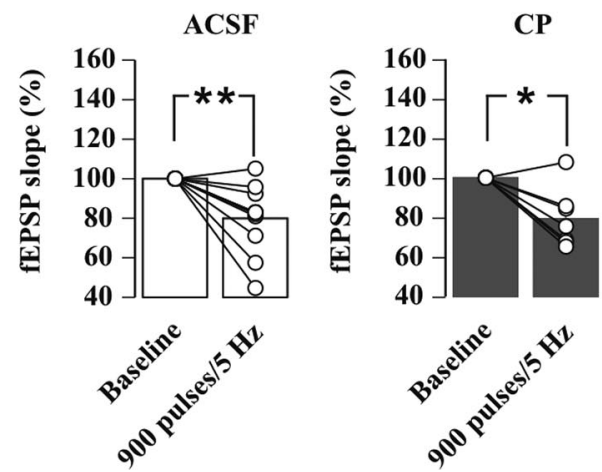

Figure 4. Activation of NR2A-NMDARs is required for SD-induced 5 Hz-LTD. $A, B$, Field EPSP slopes (percentage of baseline) recorded in slices from sleep-deprived mice. $\boldsymbol{A}$, Top, Sample fEPSP traces, representative for times indicated by numbers, and their superposition. Middle, Time course of average fEPSP slopes for $5 \mathrm{~Hz}$ conditioning experiments in drug-free conditions (ACSF, white circles, $n=4$ ) and in $50 \mathrm{~nm} \mathrm{NVP} \mathrm{(gray} \mathrm{circles,} n=7$ ). Bottom, Histograms depicting mean values of synaptic strengths (bars), quantified in the last 10 min of postconditioning, with values for individual experiments overlaid (circles connected by lines). Note that $5 \mathrm{~Hz}$-LTD was observed in all the ACSF experiments $\left({ }^{* *} p<0.005\right.$, paired $t$ test), but only in 2 out of 7 experiments after NVP application ( $p=0.36$, paired $t$ test). $\boldsymbol{B}$, As $A$, but the effects of $\mathrm{CP}(10 \mu \mathrm{m})$ on $5 \mathrm{~Hz}$-LTD were tested. $5 \mathrm{~Hz}$-LTD was observed in 8 out of 11 ACSF experiments $\left({ }^{* *} p<0.005\right.$, paired $t$ test $)$ and in 6 out of 7 experiments after $\left(P\right.$ application $\left({ }^{*} p<0.02\right.$, paired $t$ test).

selective antagonist (Köhr, 2006), and NVP (50 nM), an NR2Apreferential antagonist (Berberich et al., 2005; Bartlett et al., 2007), were tested individually on NMDAR-EPSCs elicited in the hippocampal CA1 area via stimulating Schaffer collaterals and measured using whole-cell patch-clamp recordings (see Materials and Methods). Under these conditions, NMDAR-EPSC amplitudes were $-39.5 \pm 4.2 \mathrm{pA}$ in NR2A KO mice $(n=16)$ and $-55.2 \pm 5.7 \mathrm{pA}$ in WT mice $(n=17)$ at holding potentials of -30 to- $35 \mathrm{mV}$ to partially relieve the pore block by $\mathrm{Mg}^{2+}$. Current decay time, quantified by dividing the charge transfer by the peak amplitude of the EPSCs (see Materials and Methods) (ArnthJensen et al., 2002; Bellone and Nicoll, 2007), was markedly slower in cells from NR2A KO $(176.9 \pm 13.4 \mathrm{~ms}, n=16) \mathrm{com}-$ pared with WT mice $(42.4 \pm 2.3 \mathrm{~ms}, n=17 ; p<0.0001)$. In NR2A KO mice, NVP bath-applied at $50 \mathrm{~nm}$ attenuated the NMDAR-EPSCs by $20.3 \pm 9.1 \%$, with marginal significance $(n=$ $9, p=0.05$ ) (Fig. $2 A$ ), in agreement with the minor effect of this concentration on heterologously expressed NR2B-NMDARs (Berberich et al., 2005). Conversely, $10 \mu \mathrm{M}$ CP blocked the NMDAR-EPSCs by $74.7 \pm 3.6 \%(n=6, p<0.0001)$ (Fig. $2 B)$ consistent with its submaximal antagonistic potency. In WT mice, NVP and CP reduced NMDAR-EPSCs by $48.0 \pm 4.4 \%$ $(n=6, p<0.0005)$ and $36.0 \pm 7.7 \%(n=7, p<0.005)$, respec- tively (Fig. $2 C, D)$. Decay times decelerated in NVP $(48.2 \pm 4.0$ $\mathrm{ms}$ vs $60.0 \pm 5.6 \mathrm{~ms}$ before and after NVP application, respectively, $n=6, p<0.005$ ) (Fig. $2 E$ ), but were unaltered in $\mathrm{CP}$ $(40.4 \pm 2.8 \mathrm{~ms} v \mathrm{ss} 42.5 \pm 4.2 \mathrm{~ms}, n=7, p=0.53$ ) (Fig. $2 F)$. Based on these values, we estimated the relative contributions of NR2Band NR2A-containing NMDARs to EPSCs (see Materials and Methods for detailed calculation). The submaximal antagonism of CP (Berberich et al., 2005) (Fig. 2B) and its low affinity for triheteromeric NMDARs (Chazot et al., 2002) predicted a contribution of NR2B-NMDAR diheteromers to the NMDAR-EPSC of $48 \%$ (Fig. $2 G$ ), with the remaining $52 \%$ being mediated by diand triheteromeric NR2A-containing NMDARs. NR2A- and NR2B-containing NMDARs thus generated equal portions of NMDAR-EPSCs in adult CA3-CA1 synapses, in excellent agreement with receptor subunit densities measured with EM (Fig. $1 \mathrm{~A}$, $B$ ) or using immunoprecipitation (Al-Hallaq et al., 2007). Finally, by using these estimates we further tested for the selectivity of NVP block in WT synapses. We measured experimentally and predicted theoretically the effects of coapplication of NVP and CP. Notably, the combined application of these antagonists reduced NMDAR-EPSCs from WT mice by $76.2 \pm 4.0 \%(n=5)$ (Fig. $2 H, I$ ), in excellent agreement with the predicted block when assuming two complementary subpopulations of NVP- 
A ACSF

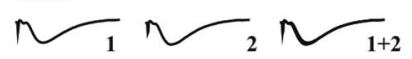

CP<smiles>CCCC</smiles>
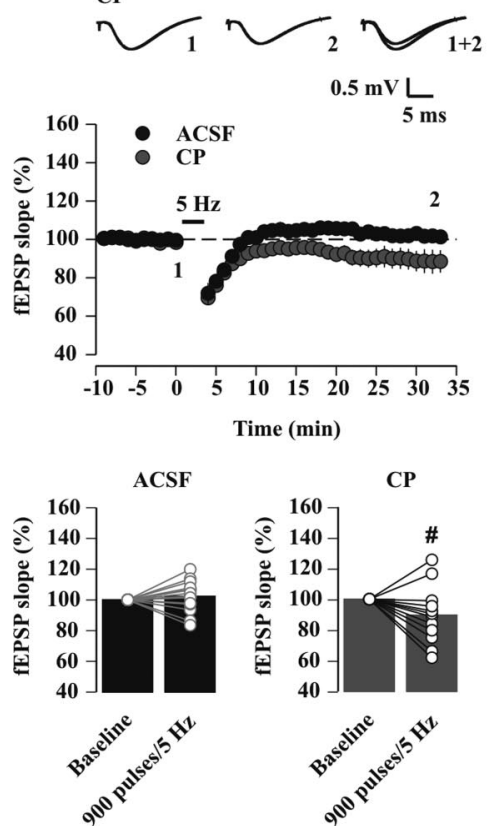

$\mathrm{CP}$

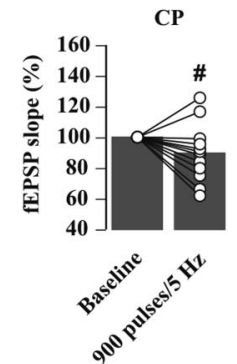

B

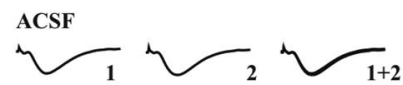

NVP

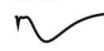

$n$
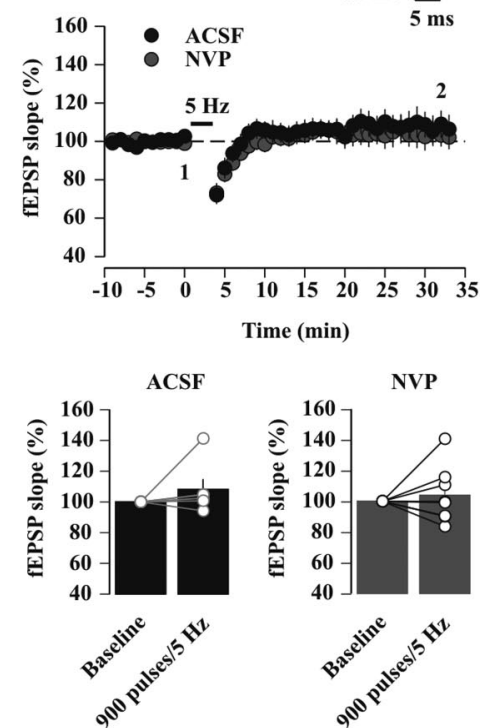

C

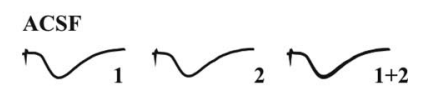

$\operatorname{APV}(11 \mu \mathrm{M})$
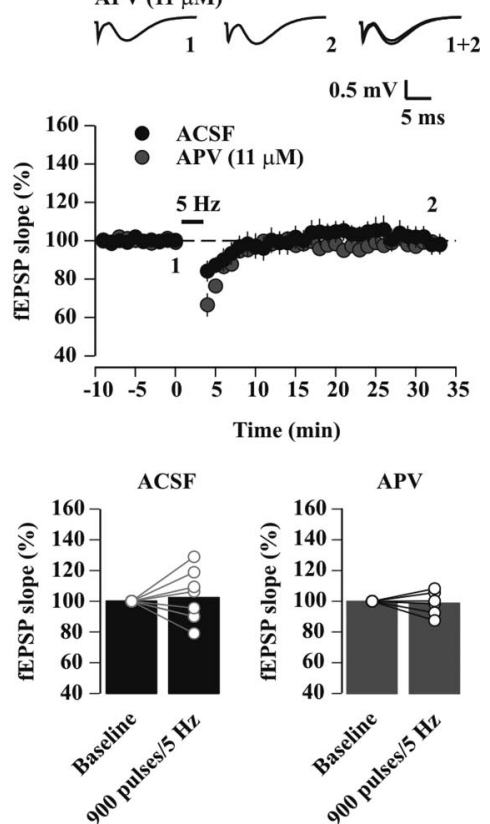

Figure 5. Pharmacologically enhancing the NR2A/NR2B ratio increases the probability to induce $5 \mathrm{~Hz}-\mathrm{LTD}$ in control undisturbed mice. $A-C$, Field EPSP slopes recorded in slices from control undisturbed mice. In all figure panels, sample traces and their superposition are shown on the top, time course of $5 \mathrm{~Hz}$ conditioning experiments in the middle, and histograms showing mean values and relative changes in individual experiments on the bottom. $A$, Time course of average fEPSP slopes (percentage of baseline) for $5 \mathrm{~Hz}$ conditioning experiments, as recorded in ACSF (black circles and bars, $n=15$ ) and in $10 \mu \mathrm{M}$ CP (gray circles and bars, $n=12) .5 \mathrm{~Hz}$-LTD was observed in 2 out of 15 experiments in ACSF ( $p=0.38$, paired $t$ test) and in 7 out of 12 experiments in CP ( $p=$ 0.07 , paired $t$ test) ( $\# p<0.02$ vs 900 pulses $/ 5 \mathrm{~Hz}$ in ACSF, unpaired $t$ test). $\boldsymbol{B}$, As $A$, but the effects of $50 \mathrm{~nm} \mathrm{NVP} \mathrm{were} \mathrm{tested.} 5 \mathrm{~Hz}$-LTD was observed in none of the ACSF experiments (black circles and bars, $n=6, p=0.29$, paired $t$ test) and in 1 out of 8 experiments after NVP application (gray circles and bars, $p=0.58$, paired $t$ test). $C$, As $A$, but the effects of $11 \mu \mathrm{m} \mathrm{D}, \mathrm{L}-\mathrm{APV}$ were tested. 5 $\mathrm{Hz}$-LTD was observed in 1 out of 8 experiments in ACSF (black circles and bars, $p=0.71$, paired $t$ test) and in 1 out of 6 experiments after D, L-APV application (gray circles and bars, $p=0.70$, paired $t$ test).

and CP-sensitive NMDARs (79\%) (see Materials and Methods). Moreover, in WT mice, the NMDAR antagonist NVP (50 nM) did not affect basal synaptic transmission through AMPARs (data not shown) or probability of release assessed by measuring the paired-pulse facilitation ratio of evoked AMPAR-EPSCs with interspike intervals of $50-100 \mathrm{~ms}(1.6 \pm 0.8$ vs $1.7 \pm 0.1$ before and after NVP application, respectively, $n=8, p=0.49$ ). Thus in adult CA1 synapses, the efficacy and selectivity of NVP were high enough to pharmacologically modulate the relative contribution of synaptic NMDAR subtypes by preferentially blocking a major component of NR2A-NMDARs.

\section{The SD-induced facilitation of LTD induction requires the activation of NR2A-NMDARs}

Using NVP and CP, as well as NR2A KO mice, we studied the role of NR2A in CA3-CA1 synaptic plasticity after sleep loss. We focused on stimulation frequencies near the modification threshold (MT) for bidirectional synaptic plasticity, known to strongly influence learning behavior (Bach et al., 1995; Zeng et al., 2001). In control undisturbed mice, a $5 \mathrm{~Hz}$ conditioning protocol (see Materials and Methods) left average synaptic strength unaltered, as measured by fEPSP slopes in the CA1 region of the hippocampus (Fig. $3 A$ ). When the outcome of $n=39$ individual experiments was plotted (Fig. 3B), a spread of data points around the baseline slope was apparent, indicating that LTD or LTP was occasionally induced $(\sim 13 \%$ and $\sim 20 \%$ of the total number of experiments, respectively). However, the half-maximal value of the cumulative distribution of fEPSP slopes (percentage of base- line) was close to baseline $(95.7 \pm 0.8 \%$, slope $=6.3 \pm 0.5)$ (Fig. $3 C$ ), confirming that most hippocampal synaptic populations remained unaltered in strength.

When $5 \mathrm{~Hz}$ conditioning of CA1 fEPSPs was applied to slices from sleep-deprived mice, an LTD averaging $84.5 \pm 2.5 \%$ of baseline fEPSP slope was observed $(n=37, p<0.0001)$ (Fig. $3 A$ ) that was abolished in the presence of the general NMDAR antagonist D,L-APV $(100 \mu \mathrm{M})$ (ACSF: $84.2 \pm 2.5 \%$ of baseline, $n=8$, $p<0.0005$; D,L-APV: $101.4 \pm 5.7 \%$ of baseline, $n=6, p=0.81$; $p<0.0005$ vs ACSF) (Fig. 3D). Inspection of the results from individual experiments showed a strongly increased probability of observing plasticity ( $~ 68 \%$ LTD and $2 \%$ LTP, $p<0.0001, \chi^{2}$ test vs control undisturbed mice) (Fig. $3 B$ ). The cumulative distribution curve of the fEPSP slopes after $5 \mathrm{~Hz}$ stimulation retained its shape, although the half-maximal value was leftward shifted to $77.3 \pm 1.1 \%$ (Fig. $3 C$ ). Therefore, after SD, $5 \mathrm{~Hz}$ conditioning produced a comparable probabilistic spread of synaptic strength, but this was biased in favor of an LTD. Taking these results together, a mild SD resulted in a shift of the MT that favors an NMDAR-dependent LTD at $5 \mathrm{~Hz}$ (5 Hz-LTD).

The $5 \mathrm{~Hz}$-LTD in slices from sleep-deprived mice $(73.4 \pm$ $3.5 \%$ of baseline, $n=4, p<0.005$ ) was prevented by $50 \mathrm{~nm} \mathrm{NVP}$ ( $96.8 \pm 3.3 \%$ of baseline, $n=7, p=0.36 ; p<0.001$ vs ACSF) with only two out of seven experiments inducing an LTD (Fig. $4 A$ ). Conversely, $5 \mathrm{~Hz}-\mathrm{LTD}$ was preserved in $10 \mu \mathrm{M} \mathrm{CP}$ (ACSF: $79.8 \pm 5.1 \%$ of baseline, $n=11, p<0.005$; CP: $79.1 \pm 5.7 \%$ of baseline, $n=7, p<0.02 ; p=0.47$ vs ACSF) (Fig. $4 B$ ). This effect of NVP could be explained by a reset of the MT to control values. 

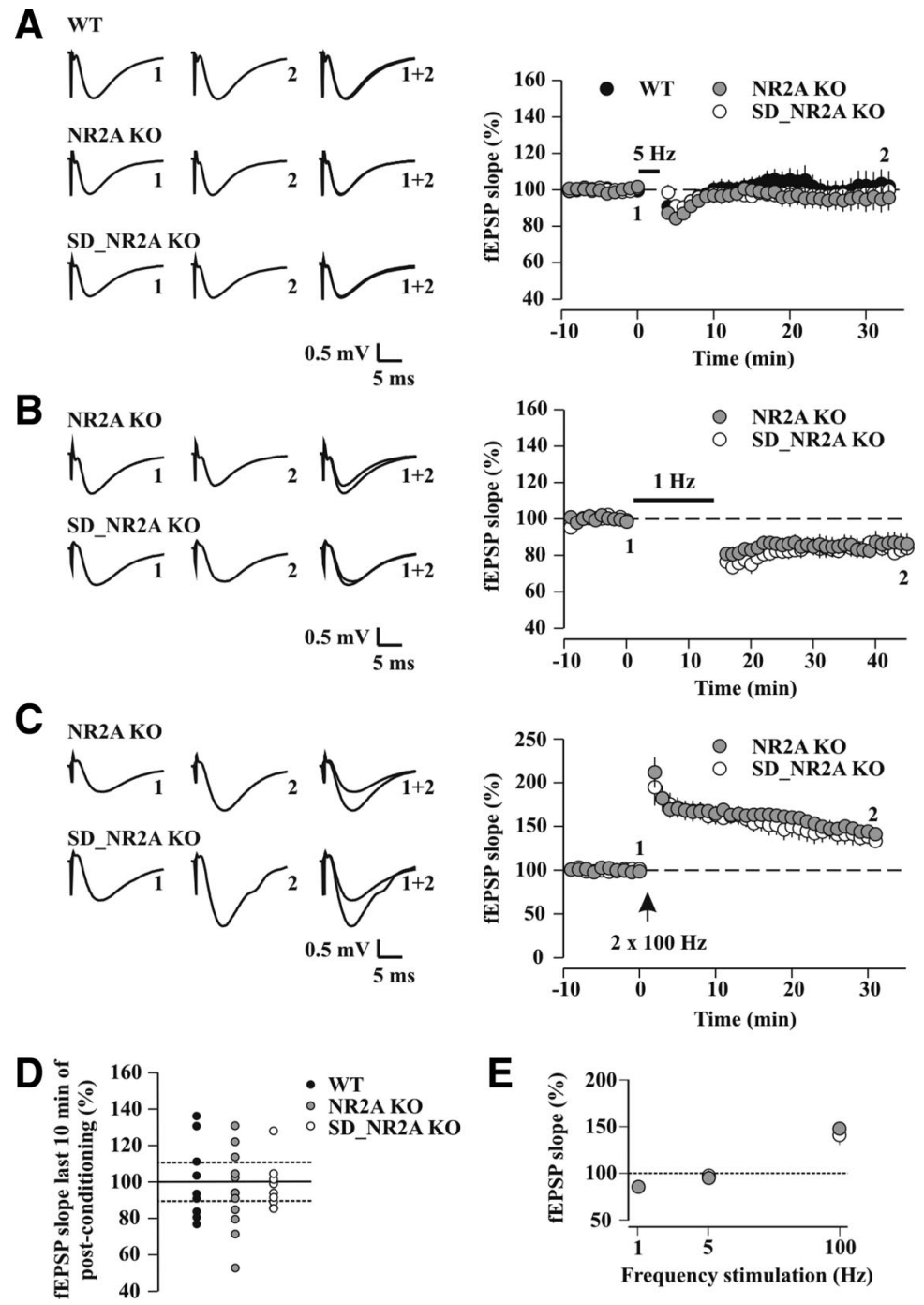

Figure 6. In NR2A KO mice, $5 \mathrm{~Hz}$ plasticity is unaltered in undisturbed conditions, and bidirectional synaptic plasticity is no longer sensitive to SD. A, Time course of average fEPSP slopes before and after a $5 \mathrm{~Hz}$ conditioning protocol in WT (black circles, $n=9$ ), control undisturbed NR2A KO (gray circles, $n=12$ ) and sleep-deprived NR2A KO mice (SD_NR2A K0, white circles, $n=$ 9). Representative traces are shown to the left. $\boldsymbol{B}$, Time course of average fEPSP slopes (percentage of baseline) before and after $\boldsymbol{a}$ $1 \mathrm{~Hz}$ conditioning protocol (900 pulses) in control undisturbed NR2A K0 mice $(n=6, p<0.03$, paired $t$ test) and after SD ( $n=$ $7, p<0.001$, paired $t$ test). $C$, Time course of average fEPSP slopes (percentage of baseline) before and after a $100 \mathrm{~Hz}$ conditioning protocol (two $1 \mathrm{~s}$ pulses at $100 \mathrm{~Hz}$ separated by $30 \mathrm{~s})$ in control undisturbed NR2A KO mice $(n=6, p<0.001$, paired $t$ test) and after $\operatorname{SD}(n=6, p<0.02$, paired $t$ test). $D$, Summary data showing the distribution of synaptic strengths for individual experiments (percentage of baseline) in the last $10 \mathrm{~min}$ of postconditioning after $5 \mathrm{~Hz}$ stimulation. Same color code as $\boldsymbol{A}$. The lower and upper horizontal dashed lines are set at $10 \%$ change, the level for LTD and LTP induction. $\boldsymbol{E}$, Frequency dependence of bidirectional synaptic plasticity in control undisturbed (gray circles) and sleep-deprived (white circles) NR2A KO mice. Note that bidirectional synaptic plasticity in NR2A KO mice was insensitive to sleep loss and that the MT lay at $5 \mathrm{~Hz}$, similar to the value in WT.
Dissociable roles for NMDAR subtypes in hippocampal synaptic plasticity Previous studies emphasized that it is mainly the relative contribution of NR2Avs NR2B-NMDARs (NR2A/NR2B ratio) that underlies a sliding MT, which sets the frequency ranges over which LTD and LTP are induced (Yashiro and Philpot, 2008). However, it is unknown whether a similar mechanism could explain the effect of SD in hippocampus. We hence tested how pharmacologically augmenting or decreasing the NR2A/NR2B ratio at synapses from control undisturbed mice affected the MT. Application of $\mathrm{CP}$ to increase the NR2A/NR2B ratio augmented the probability of $5 \mathrm{~Hz}-\mathrm{LTD}$ in slices from control mice (ACSF: 2 out of 15 slices showed an LTD; CP: 7 out of 12 slices showed an LTD, $p<0.03, \chi^{2}$ test) (Fig. 5A). On average, CP induced a slight, but significant shift of the synaptic strength in response to $5 \mathrm{~Hz}$ stimulation toward an LTD (ACSF: $102.3 \pm$ $2.5 \%$ of baseline, $n=15, p=0.38$; CP: $89.5 \pm 5.4 \%$ of baseline, $n=12, p=0.07$; $p<0.02$ vs ACSF). In contrast, NVP (50 nM), reducing the NR2A/NR2B ratio, left fEPSPs unaltered (ACSF: $108.0 \pm 6.8 \%$ of baseline, $n=6, p=0.29$; NVP: $103.7 \pm$ $6.5 \%$ of baseline, $n=8, p=0.58 ; p=0.33$ vs ACSF) (Fig. 5B). Furthermore, bath application of a low concentration of D,L-APV (11 $\mu \mathrm{M})$, which nonselectively blocked NMDAR-EPSCs by an extent similar to that of CP and NVP ( $42 \%$ of inhibition, as determined from a concentration-response curve of D,L-APV) (data not shown), yet preserved the balance between NR2A- and NR2Bcontaininag receptors, did not induce plasticity (ACSF: $102.2 \pm 5.9 \%$ of baseline, $n=$ $8, p=0.71$; D,L-APV: $98.7 \pm 3.2 \%$ of baseline, $n=6, p=0.70 ; p=0.30$ vs ACSF) (Fig. 5C). The susceptibility of CA1 pyramidal neurons to a $5 \mathrm{~Hz}$ pattern of presynaptic activity appeared thus uniquely sensitive to an increase, but not to a decrease, of the NR2A/NR2B ratio. This sensitivity was apparent despite a reduced total receptor number and manifested as an augmented probability for LTD.

Alternatively, however, $5 \mathrm{~Hz}$ stimulation could have become subthreshold for LTD induction. To differentiate between these two possibilities, we measured whether a slightly higher stimulation frequency $(10 \mathrm{~Hz})$ (see Materials and Methods) favored LTD or LTP. After SD, fEPSPs were potentiated in NVP in response to $10 \mathrm{~Hz}$ conditioning $(123.2 \pm 2.9 \%$ of baseline, $n=5, p<0.01$ ), with LTP observed in five out of five experiments. Together, these data show that a specific blockade of NR2B-NMDARs did not alter $5 \mathrm{~Hz}$-LTD after SD, whereas a preferential attenuation of NR2A-containing receptors by NVP was sufficient to prevent plasticity, likely by reversing the dominant presence of NR2A-NMDARs and resetting the MT to control values.
One concern was that NVP blocks NR2A-NMDARs incompletely and could thus mask a possible leftward shift of the MT through insufficiently decreasing the NR2A/NR2B ratio. Therefore, we examined bidirectional synaptic plasticity at hippocampal CA3-CA1 synapses in NR2A KO mice, which show a dramatic leftward shift of the MT in visual cortex (Philpot et al., 2007). Surprisingly, the absence of the NR2A subunit protein did neither alter the susceptibility of CA1 pyramidal neurons to a $5 \mathrm{~Hz}$ conditioning pattern (WT: $100.7 \pm 7.1 \%$ of baseline, $n=9, p=$ 0.92; NR2A KO: $95.0 \pm 6.3 \%$ of baseline, $n=12, p=0.35 ; p=$ 0.36 vs WT) (Fig. $6 A$ ) nor the probability of observing plasticity $\left(\sim 33 \%\right.$ LTD and $25 \%$ LTP, $p=0.20, \chi^{2}$ test vs control undisturbed WT mice) (Fig. 6D). Moreover, at these synapses, both 
LTD and LTP could be induced by low and high frequencies of stimulation, respectively $(1 \mathrm{~Hz}$ low-frequency stimulation: $85.4 \pm 4.9 \%$ of baseline, $n=6, p<0.03$; $100 \mathrm{~Hz}$ high-frequency stimulation: $147.9 \pm 5.1 \%$ of baseline, $n=6, p<0.001$ ) (Fig. $6 B, C$ ), with $5 \mathrm{~Hz}$ still representing the MT (Fig. $6 E$ ). In the adult hippocampus, NR2B-NMDARs are thus competent for inducing both LTP (Sakimura et al., 1995; Kiyama et al., 1998) and LTD, but they do not control the location of the MT along the frequency axis. In conclusion, the role of NR2A-NMDARs in controlling the MT of CA1 is dissociated from that of NR2B-NMDARs.

\section{Obligatory role for NR2A-NMDARs in the SD effects \\ on the MT}

The importance of NR2A-NMDARs in setting the MT predicted that the NR2A subunits were indispensable for the SDinduced shift of hippocampal MT. Accordingly, we tested the impact of SD on NR2A KO mouse behavior and plasticity. Previous electroencephalographic recordings showed unaltered slow-wave sleep duration and intensity in these mice (Miyamoto et al., 2003). We found that NR2A KO mice were well entrained to the light-dark cycle and showed an amount of resting time comparable to that of WT littermates that were monitored in the same session (Fig. 7A) (see Materials and Methods). The duration of SD, which is determined by the spontaneous behavior of the animals, was equal for NR2A KO (5.0 $\pm 0.2 \mathrm{~h} ; n=9)$ and WT littermates $(4.6 \pm 0.4 \mathrm{~h} ; n=6 ; p=0.30)$. The level of activity, expressed as mean distance traveled per hour of SD, was also comparable (NR2A KO: $108.0 \pm 6.6 \mathrm{~m} / \mathrm{h}$; WT: $112.8 \pm 6.7 \mathrm{~m} / \mathrm{h}, p=0.63$ ) (Fig. $7 B$ ). Once mice fell asleep, they were left completely undisturbed and resting time over the recovery period was monitored. Both sleep-deprived WT and NR2A KO mice showed enhanced resting time during the first hours of recovery compared with their own baseline rest (WT: hour $1, p<0.02$; hour $2, p=0.26$; hour 3, $p=0.39$; NR2A KO: hour $1, p<0.03$; hour 2, $p<0.03$; hour $3, p=0.08$ ) (Fig. $7 C, D$ ). Moreover, the total resting time during the recovery period was not different between WT and NR2A KO mice ( $p>0.1)$, consistent with a comparable amount of recovery. Next, we measured the impact of SD on bidirectional synaptic plasticity in slices prepared from NR2A KO mice. SD did not unravel a $5 \mathrm{~Hz}-\mathrm{LTD}(97.5 \pm 4.4 \%$ of baseline, $n=9, p=0.58$; $p=0.76$ vs NR2A KO in undisturbed conditions) (Fig. $6 A, D$ ). Moreover, $1 \mathrm{~Hz}$-LTD and $100 \mathrm{~Hz}$-LTP levels in sleep-deprived NR2A KO mice were similar to those of control undisturbed littermates ( $1 \mathrm{~Hz}$ low-frequency stimulation: $84.2 \pm 3.8 \%$ of baseline, $n=7, p<0.001 ; p=0.85$ vs NR2A KO in undisturbed conditions; $100 \mathrm{~Hz}$ high-frequency stimulation: $140.9 \pm 10.5 \%$ of baseline, $n=6, p<0.02 ; p=0.56$ vs NR2A KO in undisturbed conditions) (Fig. 6B, C). Therefore, the NR2A subunit is both necessary and sufficient for shifting the MT, and its deletion renders CA3 to CA1 bidirectional synaptic plasticity insensitive to $\mathrm{SD}$ (Fig. $6 E$ ). In contrast, genetic removal of NR2A did not prevent behavioral compensatory processes of sleep homeostasis,
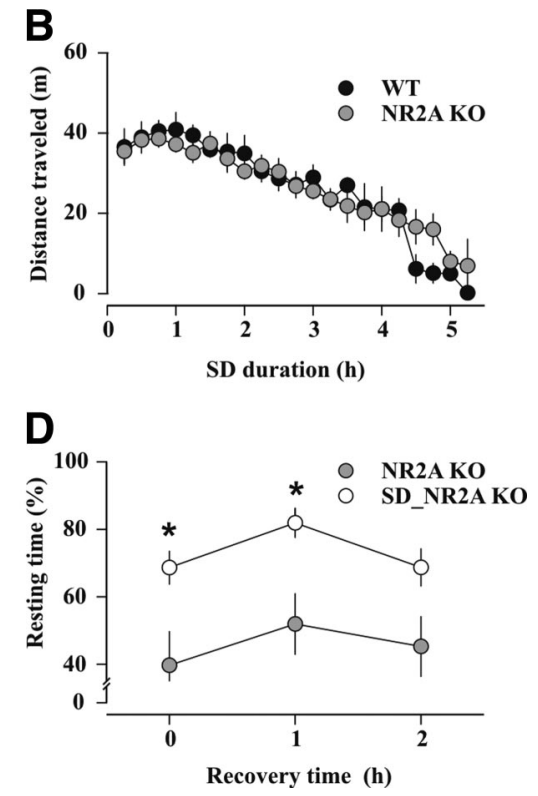

Recovery time (h) WT
SD WT

Recovery time (h)

Figure 7. NR2A KO mice show largely preserved behavioral response to SD. $\boldsymbol{A}$, Hourly time course of home-cage resting time (percentage of recording time) during the recovery period after SD (white circles) and during baseline conditions in WT (C, black circles) and NR2A KO ( $\boldsymbol{D}$, gray circles) mice. ${ }^{*} p<0.05$ (paired $t$ test vs baseline conditions).

such as increased rest after SD (Kapfhamer et al., 2002; Kopp et al., 2006).

\section{Elevated NR2A-NMDAR synaptic content alters the temporal} profile of NMDAR-EPSC summation

CA3-CA1 hippocampal synaptic plasticity requires the repetitive activation of NMDARs. The characteristics of the corresponding temporally summated currents have been proposed to set the direction of synaptic plasticity (Philpot et al., 2001; Popescu et al., 2004; Erreger et al., 2005).

To define the role of NR2A-NMDARs during $5 \mathrm{~Hz}$ stimulation, we tracked NMDAR subtype activation during temporal summation of NMDAR-EPSCs by applying $5 \mathrm{~Hz}$ trains of stimuli (see Materials and Methods) (Fig. 8 A). Pulse number was limited to 50 , because all characteristics of summated responses stabilized at a steady-state level. Summated NMDAR-mediated currents showed two distinct components (Fig. $8 \mathrm{~B}, \mathrm{C}$ ). A phasic current remained fairly constant during the train, except for a short-term depression at train onset. A persistent current started from the first stimulus but then increased gradually, reaching a steady-state after $\sim 20$ stimuli (last 10 pulses average: $0.41 \pm 0.20$ when normalized to the first peak amplitude, $n=34$ ). A slowly decaying current, which we are referring to as tail current, was observed at the end of the $5 \mathrm{~Hz}$ train of stimuli. In $\mathrm{CP}$, minimizing NR2B-NMDAR contribution, total EPSC summation was moderately altered compared with drug-free recordings (last 10 pulses average in ACSF: $1.39 \pm 0.13$ of the first peak; CP: $1.24 \pm 0.12$, $n=9 ; p<0.03$ ) (Fig. $8 D$ ), whereas the persistent current component was clearly reduced (last 10 pulses average in ACSF: $0.44 \pm 0.05$ of the first peak; CP: $0.29 \pm 0.04, n=9 ; p<0.0002)$. $\mathrm{CP}$ did not affect phasic NMDAR-EPSCs (second pulse/first pulse in ACSF: $0.81 \pm 0.08$; CP: $0.71 \pm 0.06, n=9 ; p=0.11$; last 10 pulses average in ACSF: $0.95 \pm 0.09$ of the first peak; CP: $0.95 \pm 0.10, n=9 ; p=0.96)$. To study NR2B-NMDAR function, temporal summation of NMDAR-EPSCs was addressed in slices 
A

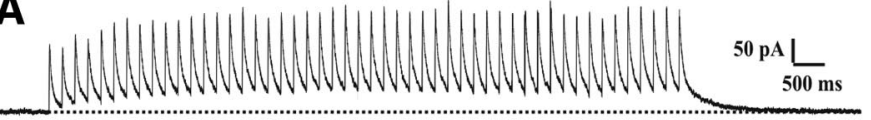

B

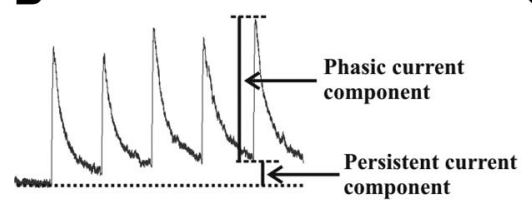

C

D

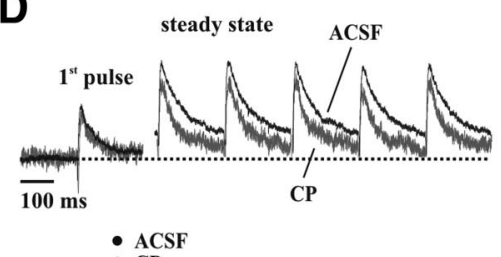

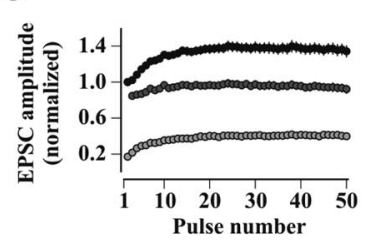

$\mathbf{E}$

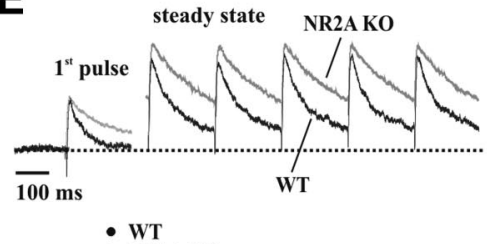

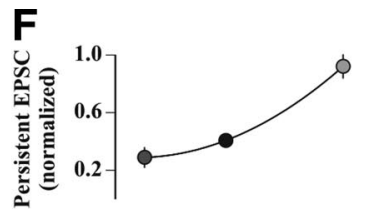

- WT

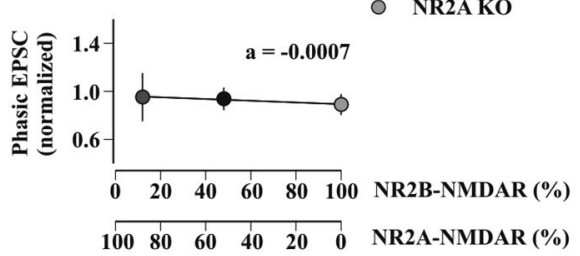

G

G steady state
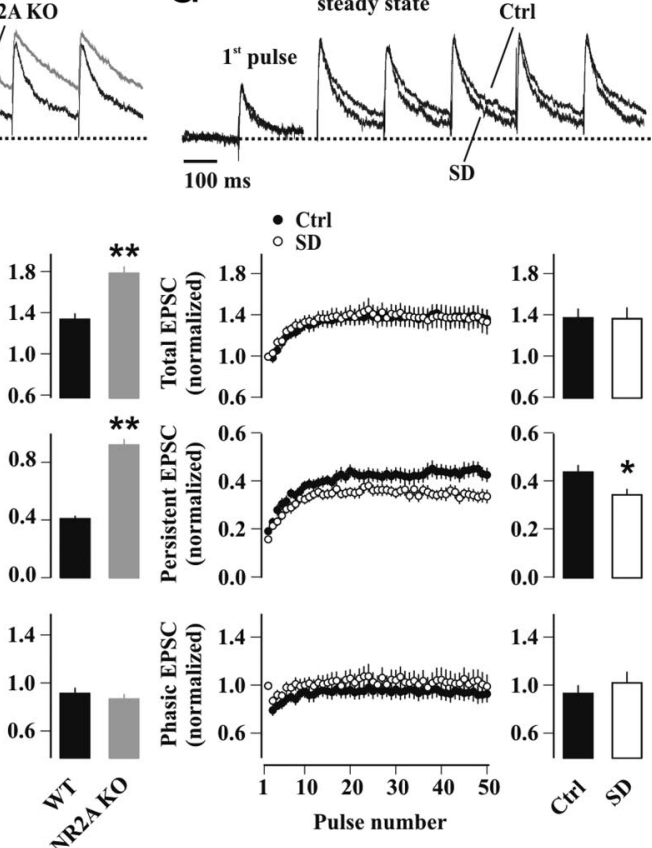

Figure 8. The NR2A/NR2B ratio sets characteristic properties of temporal summation of NMDAR-EPSCs during $5 \mathrm{~Hz}$ stimulation. $A$, Representative train of 50 NMDAR-EPSCs elicited at $5 \mathrm{~Hz}$ in a slice from a control undisturbed WT mouse, obtained from the average of three consecutive sweeps. The horizontal dashed line indicates the baseline value of the holding current before $5 \mathrm{~Hz}$ stimulation. $B$, Enlarged section of the first five responses of the train shown in $\boldsymbol{A}$, with arrows indicating the persistent and phasic current components. $\boldsymbol{C}$, Average time course of the total (black circles), phasic (dark gray circles) and persistent (light gray circles) current components during $5 \mathrm{~Hz}$ stimulation trains in control undisturbed WT mice $(n=34)$. All currents were normalized to the amplitude of the first peak (97.1 $\pm 7.0 \mathrm{pA} ; n=34)$. D, Effect of CP on temporal summation. Top, Representative traces of responses to the first pulse in the train and of steady-state responses (40th to 45th pulses), scaled to the first EPSC. Bottom, Temporal development (left) and steady-state values (right, average of the last 10 pulses) of the total (upper panel), persistent (middle panel) and phasic (lower panel) current components in drug-free conditions (ACSF, black circles and bars) and following bath-application of $10 \mu \mathrm{M} C P$ (dark gray circles and bars) in slices from control undisturbed WT mice. NMDAR-EPSC amplitudes were normalized to that of the first peak (ACSF: $86.5 \pm 9.6 \mathrm{pA} ;\left(\mathrm{CP}: 49.1 \pm 6.1 \mathrm{pA}, n=9\right.$ ). ${ }^{*} p<0.03 ;{ }^{* *} p<0.0002$ (paired $t$ test). $\boldsymbol{E}$, Same experiment as $\boldsymbol{D}$, performed for NR2A KO mice (light gray circles and bars) and WT littermates (black circles and bars) in control undisturbed conditions. NMDAR-EPSCs were normalized to the amplitude of the first peak in the train (WT: 97.1 $\pm 7.0, n=34$; NR2A K0: $102.3 \pm 9.1 \mathrm{pA}, n=11$ ). ${ }^{* *} p<0.0001$ (unpaired $t$ test). $\boldsymbol{F}$, Plot of normalized persistent (upper panel) and phasic (lower panel) current components (last 10 pulses average) versus the relative contribution of NR2A- and NR2B-NMDARs (WT, black circles; WT_CP, dark gray circles; NR2A K0, light gray circles). $\mathbf{G}$, Same experiment as $\boldsymbol{D}$ and $\boldsymbol{E}$, performed for WT animals in control undisturbed conditions (Ctrl; black circles and bars) and after SD (white circles and bars). NMDAR-EPSC amplitudes were normalized to that of the first peak in the train (Ctrl: $83.1 \pm 9.4, n=18 ; \mathrm{SD}: 84.7 \pm 5.5 \mathrm{pA}, n=16$ ). ${ }^{*} p<0.03$ (unpaired $t$ test).

from NR2A KO mice (Fig. 8E). Here, persistent current components were $>2$-fold greater (last 10 pulses average: $0.92 \pm 0.04$ of the first peak, $n=11 ; p<0.0001$ vs WT), and total current summation strongly augmented (last 10 pulses average: $1.81 \pm$ 0.07 of the first peak, $n=11 ; p<0.0005$ vs WT). The profile of phasic current components remained unaffected (second pulse/ first pulse: $0.87 \pm 0.04$; last 10 pulses average: $0.89 \pm 0.04$ of the first peak, $n=11 ; p=0.58$ vs WT).

Across the two extremes of predominantly NR2A- to exclusively NR2B-containing synapses, the persistent current component of summated NMDAR-EPSCs was most sensitively regulated by the NR2A/NR2B ratio. A plot of the normalized persistent current amplitudes against the relative contribution of the NMDAR sub- types yielded a nonlinear relation between these two parameters, whereas phasic current components were independent of NMDAR subtype content (Fig. $8 F$ ).

This relation was used to predict the NR2A/NR2B ratio at CA1 synapses after SD. Total temporal summation remained unaffected compared with control undisturbed mice (last $10 \mathrm{~min}$ average in sleep-deprived mice: $1.37 \pm 0.11$ of the first peak, $n=16$; control mice: $1.38 \pm 0.09, n=18 ; p=0.96$ ), but the contribution of the persistent current component was reduced to $78 \%$ of control undisturbed animals (last 10 pulses average, $p<0.03$ vs control mice) (Fig. $8 G$ ), yielding an NR2A/NR2B ratio of $\sim 1.8$ (64\% and 36\% for NR2A- and NR2B-containing receptors, respectively) (Fig. $8 F$ ). This value is in excellent agreement with 
that obtained from EM (NR2A/NR2B ratio of $\sim 1.6$ ), strongly suggesting that the enriched NR2A proteins were integrated into functional NMDARs.

\section{SD does not affect AMPAR-mediated responses evoked by $5 \mathrm{~Hz}$ stimulation trains}

Experience-dependent changes in shortterm plasticity of glutamatergic synaptic transmission have been described (Finnerty et al., 1999; Yashiro et al., 2005). To study the possible impact of SD on CA3 to CA1 short-term plasticity during nearthreshold repetitive stimulation, we tracked the behavior of AMPAR-EPSCs in response to $5 \mathrm{~Hz}$ trains of 50 pulses (see Materials and Methods). In control undisturbed WT animals, AMPAR-mediated current amplitudes showed a minor paired-pulse facilitation (second pulse/first pulse: $1.13 \pm 0.05, n=10, p<0.04$ ) (Fig. 9), then progressively decreased, eventually reaching levels equal to those of the first pulse (last 10 pulses average: $0.95 \pm 0.09$ of the first peak, $n=10$, $p=0.62$ ). The behavior of AMPAR-EPSCs during $5 \mathrm{~Hz}$ repetitive stimulation was unaltered after SD (second pulse/first pulse: $1.00 \pm 0.05, n=11 ; p=0.09$ vs control mice; last 10 pulses average: $0.99 \pm 0.14$ of the first peak, $n=11, p=0.78$ vs control mice) (Fig. 9). These data indicate that the temporal profile of AMPAR-EPSC summation in response to $5 \mathrm{~Hz}$ stimulation was not altered by SD and argue against major alterations in presynaptic release characteristics.

\section{SD alters the balanced activation of synaptically located NR2A-NMDARs and of slowly recruited NR2B-NMDARs during repeated $5 \mathrm{~Hz}$ stimulation}

The mechanistic basis rendering persistent currents exquisitely sensitive to the NR2A/NR2B ratio and to SD was next addressed. Synaptic current components accruing during repetitive stimulation could arise from incomplete decay of NMDAR-EPSCs, thereby boosting slowly decaying (NR2B-type) EPSC components (Popescu et al., 2004; Erreger et al., 2005). Furthermore, recruitment of receptors located more distantly from the glutamate source could account for slowly rising NMDAR currents (Diamond, 2001; Arnth-Jensen et al., 2002; Lozovaya et al., 2004; Harris and Pettit, 2008). To study the role of current decay, the persistent current resulting from linear summation of NMDAREPSCs was calculated. A linear superposition of exponential fits to the decay of NMDAR-EPSCs recorded in a subset of experiments (WT, $n=8$; NR2A KO, $n=8$; see Materials and Methods) yielded a persistent current at the end of the train that equaled $0.18 \pm 0.03$ and $0.48 \pm 0.02$ of the amplitude of the first NMDAR-EPSC for WT and NR2A KO, respectively (Fig. 10A, B). These values were markedly smaller than those measured experimentally (last 10 pulses average in WT: $0.43 \pm 0.04$ of the first peak, $p<0.005$ vs linear summation; NR2A KO: $0.88 \pm 0.05, p<$ 0.0002 vs linear summation; $n=8$ each) (Fig. $10 A, B$ ). Reaction rate models of NMDAR subtypes (Popescu, 2005) (S. A. AmicoRubio and G. K. Popescu, unpublished data) (Fig. 10C) were next used to model the behavior of NMDAR-mediated currents (see Materials and Methods). In response to a single glutamate pulse, the NR2A- and NR2B-NMDAR reaction schemes generated $44.0 \%$ and $56.0 \%$ of an NMDAR-EPSC, respectively. These values are in reasonable agreement with those obtained experimen- tally (NR2A-NMDAR, 52\%; NR2B-NMDAR, 48\%) (Fig. 2). However, these models did not reproduce NMDAR-mediated currents arising from $5 \mathrm{~Hz}$ trains of glutamate pulses (Fig. $10 \mathrm{D}$ $F$ ). The NR2A-NMDAR model generated a negligible persistent current (Fig. 10D), whereas the NR2B-NMDAR model gave rise to an instantaneous, step-like, persistent current (Fig. 10E) that was comparable to that predicted by linear summation of decay kinetics of NMDAR-EPSCs recorded in NR2A KO mice (Fig. $10 \mathrm{~B})$. When the responses of receptor subtypes were added at the experimentally determined ratio (52\% and $48 \%$ for NR2A- and NR2B-NMDARs, respectively), a minor and time-invariant persistent current was obtained (Fig. $10 \mathrm{~F}$ ). These findings indicate that incomplete current decay could neither account for extent nor gradual nature of persistent currents in the $5 \mathrm{~Hz}$ train.

We thus evaluated the possibility that additional receptor pools accessible by the released glutamate, but recruited on slower time scales, could contribute to the persistent current. First, the pharmacological profile of current components over the course of a train was assessed (Fig. 11A). The effect of CP on the phasic current amplitudes remained stable during the train (first pulse: $43.2 \pm 4.7 \%$ of inhibition; last 10 pulses average: $40.7 \pm 6.5 \%$ of inhibition, $n=9, p=0.53$ ) (Fig. $11 A, B$ ), but persistent currents displayed a linearly increasing sensitivity to CP (first pulse: $42.6 \pm 7.0 \%$ of inhibition; last 10 pulses average: $63.8 \pm 3.7 \%$ of inhibition, $p<0.03 ; p<0.02$ vs inhibition of phasic current). This incremental difference (Fig. 11A-C) pointed to a gradual recruitment of NR2B-NMDARs that specifically contributed to the late component of each pulse. Second, the stimulation train was followed by a tail current $($ Fig. $11 D)$ and (Lozovaya et al., 2004), which reflects the decay of NMDARs activated by the glutamate accumulated during the train, including those contributing to the persistent current. The tail current decayed more slowly than NMDAR-EPSCs (decay time: single pulse, $71.6 \pm 2.7 \mathrm{~ms}$; tail current, $180.7 \pm 5.3 \mathrm{~ms}, n=34, p<$ 0.0001 ) (Fig. $11 D$ ) and was markedly accelerated by CP (decay time of tail current: ACSF, $175.8 \pm 7.3 \mathrm{~ms}$; CP, $92.6 \pm 12.6 \mathrm{~ms}$, $n=6, p<0.002$ ) (Fig. $11 E$ ). Therefore, NR2B-NMDARs dominated tail current properties. Third, we exploited the effects of the low-affinity competitive NMDAR antagonist D-aminoadipic acid (D-AA), whose efficacy depends on the glutamate concentration (Clements et al., 1992; Diamond, 2001). D-AA $(70 \mu \mathrm{M})$ reduced both amplitude (ACSF: $127.8 \pm 11.6 \mathrm{pA}$; D-AA: $59.2 \pm 5.5 \mathrm{pA}, n=7, p<0.001$ ) and decay time (ACSF: $83.2 \pm 3.4 \mathrm{~ms}$; D-AA: $60.1 \pm 4.5 \mathrm{~ms}, n=7, p<0.001$ ) (Fig. $11 F$ ) 
A
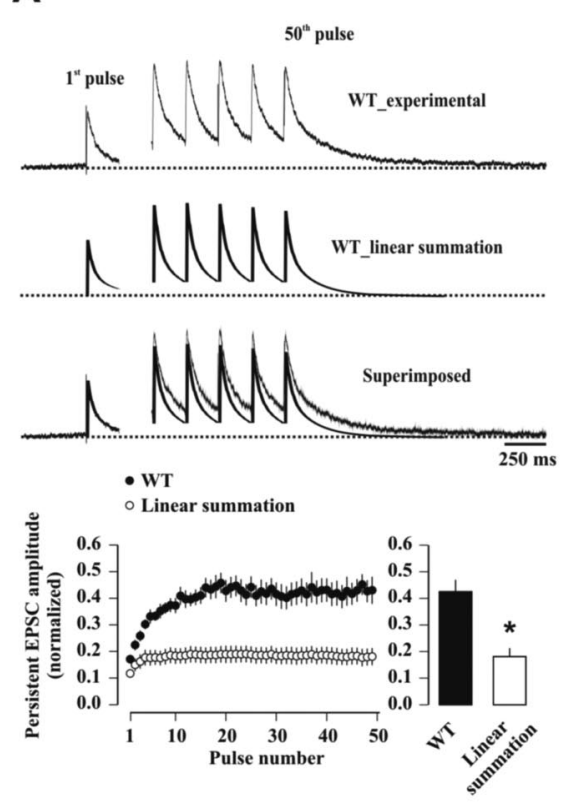

C
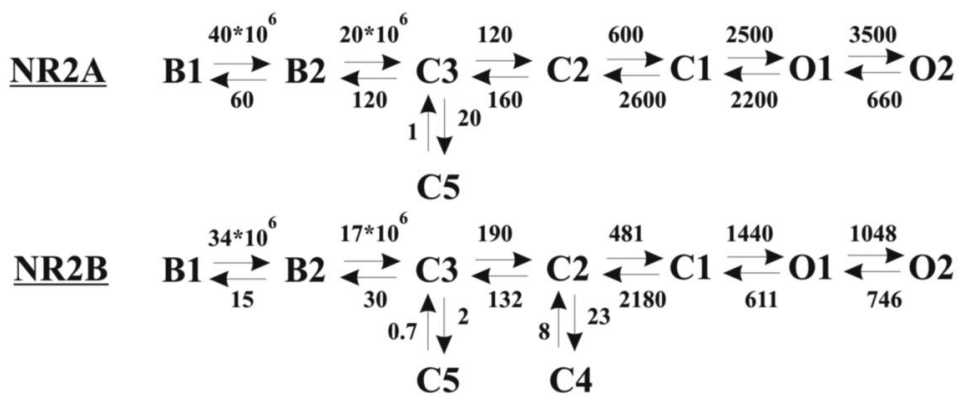

D

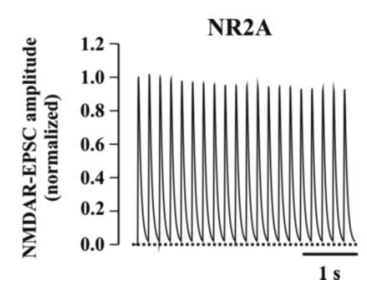

C5

B
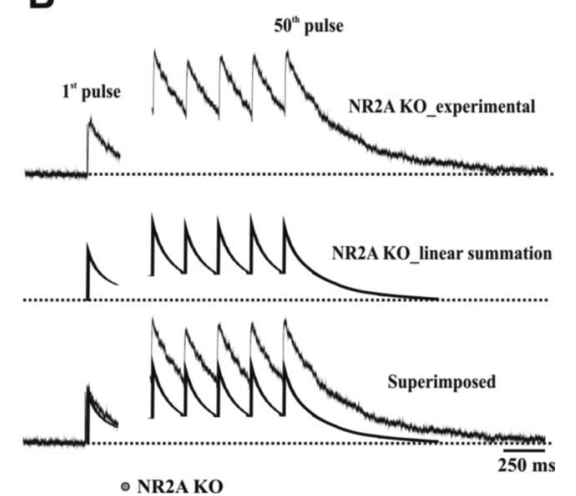

$\circ$ Linear summation

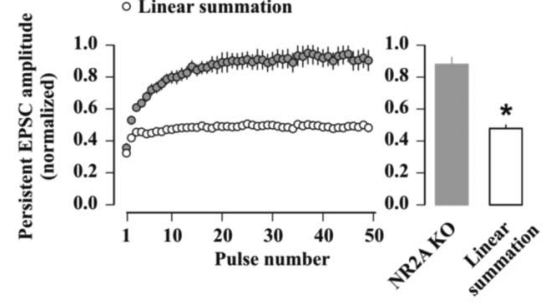

E

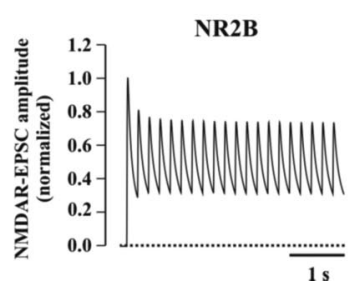

$\mathbf{F}$

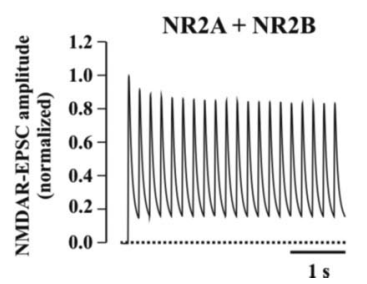

Figure 10. Linear summation of NMDAR-EPSCs and computational models of NMDAR subtypes do not reproduce slowly rising persistent currents during $5 \mathrm{~Hz}$ stimulation. $\boldsymbol{A}, \boldsymbol{B}$, Summation of biexponential fits of NMDAR-EPSC decay times, scaled according to the amplitudes of experimentally measured phasic currents for WT $(\boldsymbol{A})$ and NR2A KO $(\boldsymbol{B})$ mice. Top traces represent experimentally measured currents, middle trace linear summation of NMDAR-EPSC exponential fits, and bottom traces the superposition of the two. Time plots present the temporal summation of persistent currents measured from experimental traces (filled circles) and from linearly summated decay of NMDAR-EPSCs (open circles). ${ }^{*} p<0.005$ (paired $t$ test). C, Reaction models of NR2A- and NR2BNMDARs according to Popescu [Popescu (2005) and S. A. Amico-Rubio and G. K. Popescu, unpublished data]. Two glutamate binding steps (B1, B2) are followed by three sequential closed states (C1-C3) before receptor opening $(01,02)$. Closed state inactivation $(C 4, C 5)$ is also included in the model. Reaction rates are in $\mathrm{s}^{-1}$ with the exception of the forward rates between $\mathrm{B}$, $B 2$, and $C$, which are in $\mathrm{M}^{-1} \mathrm{~s}^{-1}$. D-F, Current responses of reaction models of NR2A- and NR2B-containing NMDARs to repeated $5 \mathrm{~Hz}$ glutamate transients. Note the complete lack of a persistent current for NR2A-NMDARs $(\boldsymbol{D})$, and the instantaneous presence of a slow persistent current for NR2B $(\boldsymbol{E})$ and for the sum of the two receptor subtypes $(\boldsymbol{F})$.

of NMDAR-EPSCs evoked by a single synaptic response, consistent with the idea that NMDARs activated by small, slow glutamate transients contributed to the late component of NMDAREPSCs (Diamond, 2001). D-AA reduced tail current amplitudes by the same extent as NMDAR-EPSCs (single pulse: $52.7 \pm 4.8 \%$ of inhibition; tail current: $55.5 \pm 7.4 \%$ of inhibition, $n=6, p=$ 0.58), but it no longer affected decay time (ACSF: $193.4 \pm 7.4 \mathrm{~ms}$; D-AA: $186.3 \pm 5.0 \mathrm{~ms}, n=6, p=0.41$ ) (Fig. 11G). This suggests that $5 \mathrm{~Hz}$ repetitive stimulation produced a more homogeneous profile of glutamate levels across different populations of NMDARs recruited during the train, enforcing in particular the contribution of NR2B-NMDARs involved in the generation of persistent currents.

When these experiments were repeated in sleep-deprived mice, it became clear that SD altered the balance of receptor subtypes recruited into the train response. First, the effect of CP on the persistent current components of the train was now comparable to that of phasic components (last 10 pulses average persistent current: $35.6 \pm 9.2 \%$ of inhibition; phasic current: $30.5 \pm 8.5 \%, n=9$, $p=0.39)($ Fig. 12A), and was lower compared with control mice $(p<0.02)$. Second, tail currents at the end of the train were strongly accelerated compared with control (SD: $136.2 \pm 8.6 \mathrm{~ms}, n=14$; control: $179.2 \pm 5.8 \mathrm{~ms}, n=13, p<0.0005)$ (Fig. 12B), consistent with an enhanced NR2A contribution. Third, decay kinetics of tail currents had largely lost CP sensitivity (ACSF: $136.2 \pm 11.4 \mathrm{~ms}$; CP: $129.6 \pm 14.4 \mathrm{~ms}, n=7, p=0.60$ ) (Fig. $12 C)$. We conclude that SD altered the properties of these summated currents by attenuating the incremental involvement of NR2B-NMDARs during repeated stimulation, while increasing the contribution of NR2A-NMDARs.

\section{Discussion}

We demonstrate here that the NR2A subunit of NMDARs is indispensable for the effects of a mild SD on hippocampal synaptic plasticity in the theta stimulation range. Conversely, its ablation renders hippocampal plasticity unresponsive to sleep loss. This function of NR2A is caused by its selective enrichment at postsynaptic densities of adult hippocampal synapses. The dominance of NR2ANMDARs interferes with the recruitment of different receptor pools during repeated glutamate release. The results indicate that altered trafficking of NR2A subunits in hippocampus is a mechanistic link between sleep loss and cellular correlates of learning and memory. Notably, rightward shifts in the MT, and in particular the appearance of LTD in the range of the theta rhythm, have been linked to an impairment of spatial reference memory (Bach et al., 1995; Migaud et al., 1998) and could hence underlie some of the detrimental effects of sleep loss on cognitive abilities (Graves et al., 2003). Conversely, spatial reference memory is unaffected in NR2A KO mice (Bannerman et al., 2008), consistent with the preserved hippocampal MT. Finally, the largely unaltered sleep-wake behavior in NR2A KO mice suggests that the NR2A subunit is not a primary determinant of post-deprivation sleep behavior. The 
A
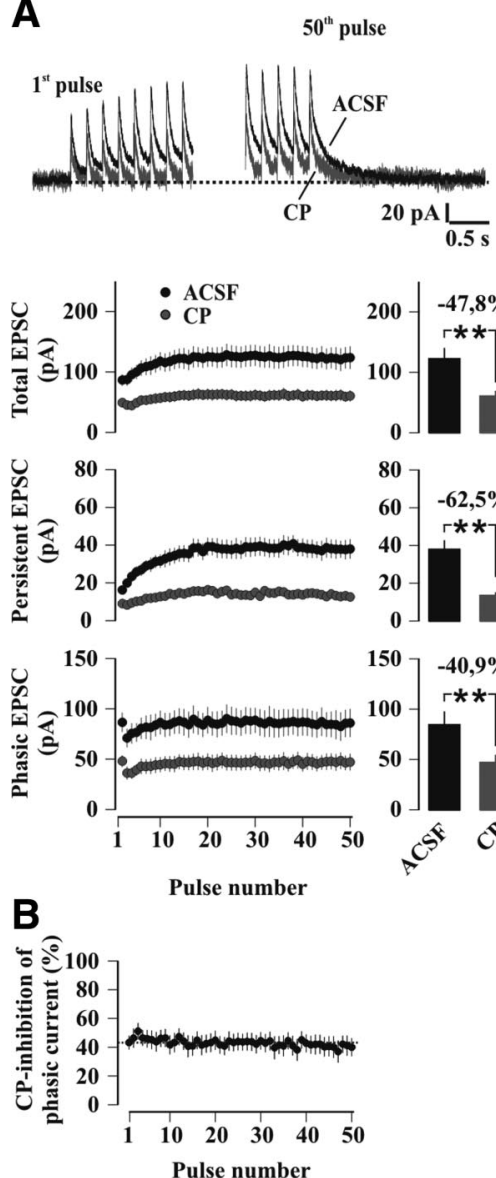

C

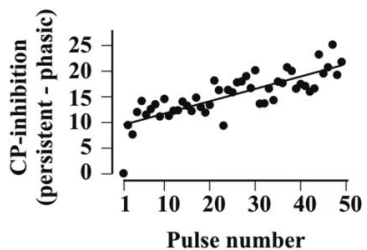

D

Single pulse

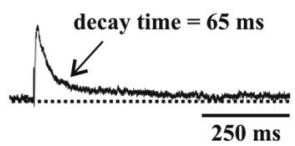

Scaled

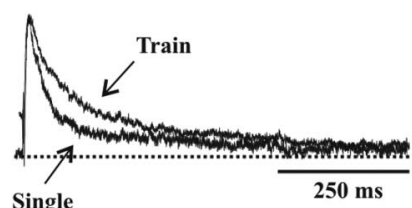

Single

E

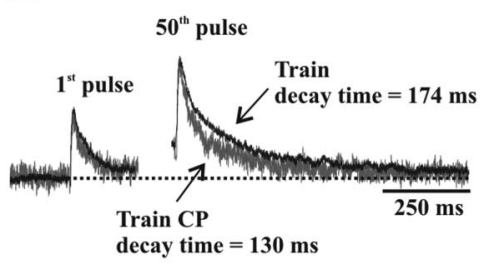

$\mathbf{F}$

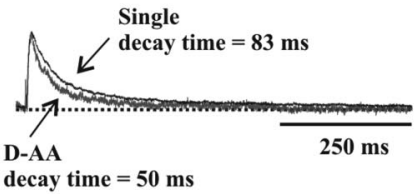

G

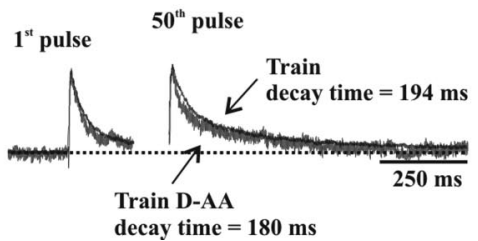

$50^{\text {th }}$ pulse
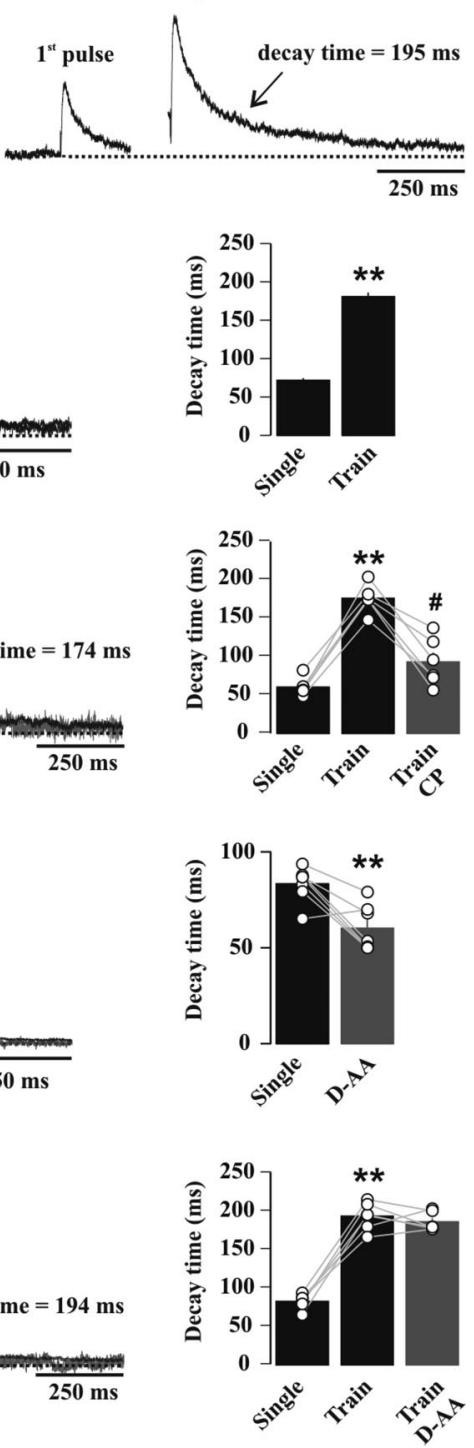

Figure 11. NMDAR pools recruited on distinct time scales contribute to temporal summation of NMDAR-EPSCS. $A-G$, All data in this figure were collected in slices from control undisturbed WT mice. $A-C$, The effects of $C P$ on persistent, but not on phasic currents, increase in the course of the train. $A$, Top, Sample traces represent sections of the first and last parts of the train in drug-free conditions (ACSF, black trace) and in (P (gray trace). The horizontal dashed line indicates the baseline holding current before the stimulation. Bottom, Amplitudes (in pA) of the total (upper panel), persistent (middle panel) and phasic (lower panel) currents in ACSF (black circles) and after bath application of $10 \mu \mathrm{M}$ CP (gray circles) $(n=9)$. Bar charts to the right of each time plot represent steady-state amplitudes (average of responses to the last 10 pulses). Amplitudes of total, persistent and phasic currents were all significantly reduced by $C P\left({ }^{* *} p<0.005\right.$, paired $t$ test). The percentage inhibition by $C P$ is indicated above each bar chart. Note that absolute current values are given in the plot rendering effects of CP evident on all current components. $B$, CP-mediated inhibition of the phasic current component versus pulse number in the train. $C$, CP-mediated inhibition of the persistent current in the course of the train, expressed as the difference from the percentage inhibition of the phasic current. A linear fit ( $y=y_{0}+a x$ ) to the values yielded: $y_{0}=9.3 \pm 0.7 \%, a=0.24 \pm 0.03 \%$ (black line), with $r=0.79$. D, Top left, Representative NMDAR-EPSC (Single pulse). Top right, The first EPSC (first pulse) and the tail current (50th pulse) of the $5 \mathrm{~Hz}$ train. Decay times are indicated next to the traces. Scaled traces are shown superimposed below. Bar chart depicts average decay times of NMDAR-EPSCS (Single) and tail currents (Train) recorded in the same cells $\left(n=34 ;{ }^{* *} p<0.0001\right.$, paired $t$ test). E, Effects of CP on tail current decay time. Sample scaled traces of NMDAR-currents are shown superimposed (ACSF, black trace; $(\mathrm{P}$, gray trace). Bars denote mean decay time values and vertical scatter plot depicts data from individual experiments $(n=6) .{ }^{* *} p<0.0001$ (paired $t$ test vs Single); ${ }^{\#} p<0.002$ (paired $t$ test vs Train). $F$, Effect of D-AA $(70 \mu \mathrm{M})$, a low-affinity competitive NMDAR antagonist, on decay time of NMDAR-EPSCs (Single). Superimposed traces are shown to the left (ACSF, black trace; $D-A A$, gray trace), bars representing mean decay time values, and vertical scatter plot showing individual experiments $(n=7)$ are superimposed on the right. ${ }^{* *} p<0.01$ (paired $t$ test vs Single). G, Effect of D-AA $(70 \mu \mathrm{m})$ on decay time of tail currents (Train). Superimposed traces are shown to the left, bars representative of mean decay time values and vertical scatter plot from individual experiments $(n=6)$ are superimposed on the right. ${ }^{* *} p<0.0001$ (paired $t$ test vs Single).

consequences of sleep loss on hippocampal synaptic plasticity appear thus conveyed through mechanisms distinct from those underlying sleep homeostasis.

\section{Specific and rapid enrichment of NR2A synaptic content after SD}

The alteration in NMDA receptor subunit composition after sleep loss is unique in specificity, restricted subcellular localization and rapid onset compared with other examples of NMDAR regulation through experience (Quinlan et al., 2004; Yashiro et al., 2005; Chen and Bear, 2007). EM revealed that SD effects were confined to a single NMDAR subtype, provoking a selective increase of NR2A expression by 1.6 -fold, while not affecting synapse size. This value is in agreement with that derived from studying temporal summation of NMDAR-EPSCs, strongly suggesting that the newly inserted protein was integrated into physiologically functional receptors. Although, the multiplicity of sleep loss 
A

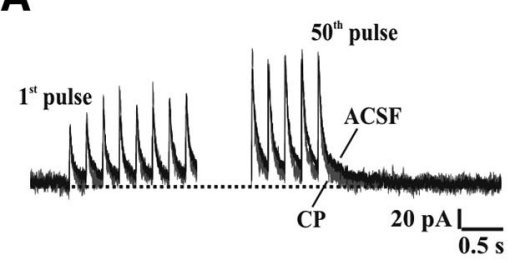

B

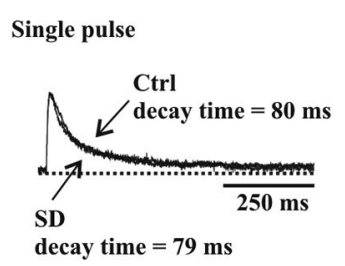

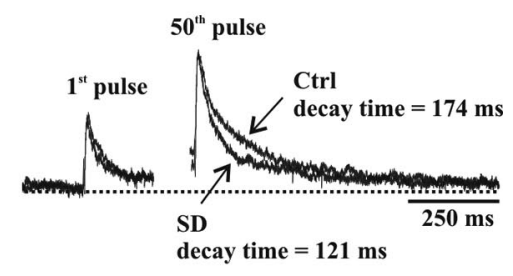

SD
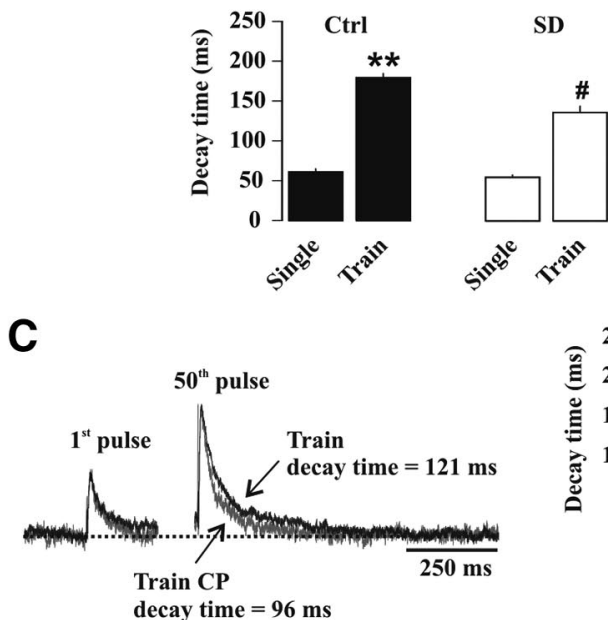

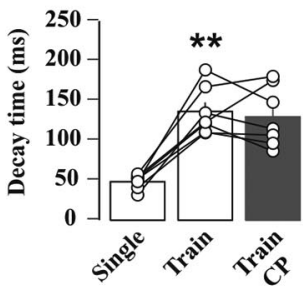

Figure 12. SD disrupts the balanced recruitment of NMDAR pools during $5 \mathrm{~Hz}$ repetitive stimulation. $\boldsymbol{A}$, Top, Sample traces represent sections of the first and last parts of the train in drug-free conditions (ACSF, black trace) and in CP (gray trace) obtained from sleep-deprived mice. The horizontal dashed line indicates the baseline value of the holding current before the stimulation protocol was applied. Bottom, Amplitudes (in pA) of the total (upper panel), persistent (middle panel) and phasic (lower panel) currents in ACSF (white circles) and after bath application of $10 \mu \mathrm{m}$ CP (gray circles) in $n=9$ sleep-deprived WT mice. Bar charts to the right of each time plot represent steady-state amplitudes (average of responses to the last 10 pulses). Amplitudes of total, persistent and phasic currents were all significantly reduced by $C P\left({ }^{*} p<0.05\right.$, paired $t$ test). The percentage inhibition by CP is indicated above each bar chart. $\boldsymbol{B}$, Top left, Representative NMDAR-EPSC (Single pulse). Top right, The first EPSC of the $5 \mathrm{~Hz}$ train (first pulse), and the tail current (50th pulse) recorded in the same cell for each condition, with decay times indicated next to the traces. Scaled traces from control undisturbed (Ctrl) and from sleep-deprived mice (SD) are shown superimposed. Bar chart depicts average decay times in Ctrl (black bars, $n=13$ ) and after SD (white bars, $n=14$ ). ${ }^{* *} p<0.0001$ (paired $t$ test vs (trl Single); ${ }^{*} p<0.0005$ (unpaired $t$ test vs Ctrl Train). C, Effects of (P on tail current decay time in slices from sleep-deprived mice. Sample scaled traces are shown superimposed (ACSF, black trace; (P, gray trace). Bars denote mean decay time values and vertical scatter plot depicts data from individual experiments ( $n=7$ ). ${ }^{* *} p<0.001$ (paired $t$ test vs Single).

effects on proteins involved in neuronal function (Cirelli, 2006; Vyazovskiy et al., 2008) does not exclude additional alterations downstream of or in parallel to NMDARs, we demonstrate here that the dominant effects of sleep loss on synaptic plasticity were obligatorily conveyed through the regulation of NR2A synaptic content.

\section{Specific control of the hippocampal plasticity threshold through NR2A-NMDARs}

The impact of experience-dependent increases in NR2A expression on hippocampal bidirectional synaptic plasticity is, at first glance, congruent with that described previously in visual cortex (Kirkwood et al., 1996; Philpot et al., 2001, 2007), including the shift of the MT toward higher frequencies and the preserved dynamic range of plasticity, delineated by the magnitude of the expressed LTD and LTP (Kirkwood et al., 1996; Philpot et al., 2001, 2007; Kopp et al., 2006).

Nevertheless, the role of NMDAR subtypes in hippocampal synaptic plasticity displayed features most distinctive from plasticity in developing visual cortex, but also from mature cortex (Quinlan et al., 2004). Most strikingly, neither partial block nor genetic deletion of the NR2A-NMDARs affected the MT of hippocampal bidirectional synaptic plasticity, in contrast to the extreme leftward shift observed in visual cortex of NR2A KO mice (Philpot et al., 2007). An important caveat in this comparison is the fact that the NMDAR component of CA1 synaptic responses appears to be reduced both in young and adult NR2A KO mice
(Sakimura et al., 1995; Ito et al., 1996), whereas it is unaltered in visual cortex (Fagiolini et al., 2003). This could attenuate NMDAR-dependent hippocampal plasticity and thus obscure an NR2B dependence of the MT position. Several experimental observations argue against this possibility. First, LTD amplitudes at $1 \mathrm{~Hz}$ were unaltered in the NR2A KO mice (Fig. 6B). Moreover, the probabilities of inducing LTD or LTP after $5 \mathrm{~Hz}$ conditioning remained at control levels (Fig. 6D), indicating that the reduced NMDA receptor component at CA1 synapses did not compromise plasticity at low stimulation frequencies. Furthermore, overexpression of NR2B only weakly shifted the hippocampal MT to the left (Tang et al., 1999). Altogether, in adult mice, the hippocampal MT appears largely independent of the dominant or exclusive presence of NR2B-NMDARs. However, it showed a clear rightward shift once NR2A/NR2B substantially $>1$ (NR2A/NR2B $\sim 1.6$ in the case of SD). As a corollary, the well documented hypothesis of a bidirectionally sliding MT, determined by a graded dependence on the NR2A/NR2B ratio in visual cortex (Philpot et al., 2001; Yashiro and Philpot, 2008), does not seem to hold for CA3 to CA1 MT, which instead shifts in a unidirectional manner. Our observations thus suggest that distinctive functional coupling of NR2A-NMDARs to LTD-promoting mechanisms at near-threshold frequencies, and a specific antagonism of these through NR2B-NMDARs, needs to be implemented to account for the unidirectional shift of hippocampal MT. Such subtype-specific actions have been described in the context of NMDAR-dependent activa- 
tion of Ras-Erk signaling (Kim et al., 2005), recruitment of protein phosphatases (Thomas et al., 1996), or CaMKII binding (Barria and Malinow, 2005).

\section{Involvement of functionally different NMDAR populations in temporal summation of NMDAR-EPSCs}

Changes in the NR2A/NR2B ratio and associated alterations in current decay kinetics have been previously shown to alter temporal summation of NMDAR-EPSCs at frequencies $>40 \mathrm{~Hz}$ (Philpot et al., 2001). Here, the temporal summation of NMDAR-EPSCs induced by a near-threshold frequency of stimulation could not be explained via a linear summation of current decay, as evident using superposition of exponential fits or repeated activation of kinetic reaction schemes for NMDARs. Instead, we found that alterations in the NR2A/NR2B ratio achieved following $\mathrm{SD}$, but also pharmacologically or genetically, sensitively affected a persistent current component that slowly accrued during repeated stimulation to levels greater than those expected from linear summation and that was predominantly carried by NR2B-containing receptors.

Slowly rising NMDAR-currents can result from delayed activation of NMDARs by gradually rising glutamate levels at periand extrasynaptic sites (Arnth-Jensen et al., 2002; Scimemi et al., 2004), and can be recruited even at low stimulation rates via intersynaptic cross talk (Diamond, 2001; Scimemi et al., 2004). Here, the late component of NMDAR-EPSCs was mediated by NMDARs activated by a low glutamate level because it could be blocked by the low-affinity NMDAR antagonist D-AA. However, the prolonged decay kinetics of the tail current were D-AAinsensitive, suggesting that $5 \mathrm{~Hz}$ repetitive stimulation enforced a delayed recruitment of NMDARs through augmenting the amount of glutamate at their sites. The comparatively greater contribution of NR2B-NMDAR subtypes to persistent currents could be explained by a number of mechanisms. First, NR2BNMDARs possess a higher sensitivity to glutamate compared with NR2A-NMDARs, suggesting that they could be preferentially recruited by slowly rising, low glutamate levels (Kutsuwada et al., 1992). Second, NR2B-containing receptors could be more accessible to glutamate escaped from the cleft, i.e., because of a higher presence at peri/extrasynaptic sites (Köhr, 2006). Finally, intersynaptic cross talk could involve small spines where NR2B receptors are preferentially expressed (Sobczyk et al., 2005). Consequently, a disrupted balance in favor of synaptic NR2A- over NR2B-containing receptors, such as that induced by SD, could substantially alter the contribution of those subtypes to synaptic currents, reduce the development of the persistent currents and result in a dominance of NR2A-NMDAR-dependent effects on synaptic plasticity.

\section{Conclusions}

This study offers a mechanistically elaborated link between NR2A, a molecular correlate of sleep loss, and its role in the susceptibility of synaptic plasticity to SD. It also provides the basis for further research on the link between sleep and learning by showing that important determinants of hippocampal synaptic plasticity can be rendered insensitive to sleep loss through ablating NR2A or by pharmacologically attenuating NR2A-NMDAR activation. For example, a next important step will be to test whether hippocampally driven forms of learning that are NR2Adependent (Bannerman et al., 2008) could be selectively vulnerable to SD, whereas NR2A-independent learning paradigms remain relatively unaffected.

Our study integrates into a series of reports documenting that
SD affects expression and function of neurotransmitter receptors in brain areas implicated in the control of waking, attention and cognition (Grivel et al., 2005; Modirrousta et al., 2007). An important aspect of sleep's beneficial functions could hence consist in maintaining and regulating protein redistribution and ion channel trafficking at central synapses (Longordo et al., 2009). In the case of hippocampal synapses, we propose that sleep could help to ensure or reset a synaptic NR2A/NR2B ratio that guarantees maximal flexibility of synapses in response to plasticitypromoting stimuli.

\section{References}

Al-Hallaq RA, Conrads TP, Veenstra TD, Wenthold RJ (2007) NMDA diheteromeric receptor populations and associated proteins in rat hippocampus. J Neurosci 27:8334-8343.

Arnth-Jensen N, Jabaudon D, Scanziani M (2002) Cooperation between independent hippocampal synapses is controlled by glutamate uptake. Nat Neurosci 5:325-331.

Bach ME, Hawkins RD, Osman M, Kandel ER, Mayford M (1995) Impairment of spatial but not contextual memory in CaMKII mutant mice with a selective loss of hippocampal LTP in the range of the theta frequency. Cell 81:905-915.

Bannerman DM, Niewoehner B, Lyon L, Romberg C, Schmitt WB, Taylor A, Sanderson DJ, Cottam J, Sprengel R, Seeburg PH, Köhr G, Rawlins JN (2008) NMDA receptor subunit NR2A is required for rapidly acquired spatial working memory but not incremental spatial reference memory. J Neurosci 28:3623-3630.

Barria A, Malinow R (2005) NMDA receptor subunit composition controls synaptic plasticity by regulating binding to CaMKII. Neuron 48:289-301.

Bartlett TE, Bannister NJ, Collett VJ, Dargan SL, Massey PV, Bortolotto ZA, Fitzjohn SM, Bashir ZI, Collingridge GL, Lodge D (2007) Differential roles of NR2A and NR2B-containing NMDA receptors in LTP and LTD in the CA1 region of two-week old rat hippocampus. Neuropharmacology 52:60-70.

Bellone C, Nicoll RA (2007) Rapid bidirectional switching of synaptic NMDA receptors. Neuron 55:779-785.

Berberich S, Punnakkal P, Jensen V, Pawlak V, Seeburg PH, Hvalby Ø, Köhr G (2005) Lack of NMDA receptor subtype selectivity for hippocampal long-term potentiation. J Neurosci 25:6907-6910.

Campbell IG, Guinan MJ, Horowitz JM (2002) Sleep deprivation impairs long-term potentiation in rat hippocampal slices. J Neurophysiol 88:1073-1076.

Chazot PL, Lawrence S, Thompson CL (2002) Studies on the subtype selectivity of CP-101,606: evidence for two classes of NR2B-selective NMDA receptor antagonists. Neuropharmacology 42:319-324.

Chen C, Hardy M, Zhang J, LaHoste GJ, Bazan NG (2006) Altered NMDA receptor trafficking contributes to sleep deprivation-induced hippocampal synaptic and cognitive impairments. Biochem Biophys Res Commun 340:435-440.

Chen WS, Bear MF (2007) Activity-dependent regulation of NR2B translation contributes to metaplasticity in mouse visual cortex. Neuropharmacology 52:200-214.

Cirelli C (2006) Cellular consequences of sleep deprivation in the brain. Sleep Med Rev 10:307-321.

Clements JD, Lester RA, Tong G, Jahr CE, Westbrook GL (1992) The time course of glutamate in the synaptic cleft. Science 258:1498-1501.

Cull-Candy SG, Leszkiewicz DN (2004) Role of distinct NMDA receptor subtypes at central synapses. Sci STKE 2004:re16.

Dang-Vu TT, Desseilles M, Peigneux P, Maquet P (2006) A role for sleep in brain plasticity. Pediatr Rehabil 9:98-118.

Davis CJ, Harding JW, Wright JW (2003) REM sleep deprivation-induced deficits in the latency-to-peak induction and maintenance of long-term potentiation within the CA1 region of the hippocampus. Brain Res 973:293-297.

Diamond JS (2001) Neuronal glutamate transporters limit activation of NMDA receptors by neurotransmitter spillover on CA1 pyramidal cells. J Neurosci 21:8328-8338.

Diamond JS, Jahr CE (1997) Transporters buffer synaptically released glutamate on a submillisecond time scale. J Neurosci 17:4672-4687.

Erreger K, Dravid SM, Banke TG, Wyllie DJ, Traynelis SF (2005) Subunit- 
specific gating controls rat NR1/NR2A and NR1/NR2B NMDA channel kinetics and synaptic signalling profiles. J Physiol 563:345-358.

Fagiolini M, Katagiri H, Miyamoto H, Mori H, Grant SG, Mishina M, Hensch TK (2003) Separable features of visual cortical plasticity revealed by $\mathrm{N}$-methyl-D-aspartate receptor 2A signaling. Proc Natl Acad Sci U S A 100:2854-2859.

Finnerty GT, Roberts LS, Connors BW (1999) Sensory experience modifies the short-term dynamics of neocortical synapses. Nature 400:367-371.

Frank MG, Issa NP, Stryker MP (2001) Sleep enhances plasticity in the developing visual cortex. Neuron 30:275-287.

Graves LA, Heller EA, Pack AI, Abel T (2003) Sleep deprivation selectively impairs memory consolidation for contextual fear conditioning. Learn Mem 10:168-176.

Grivel J, Cvetkovic V, Bayer L, Machard D, Tobler I, Mühlethaler M, Serafin M (2005) The wake-promoting hypocretin/orexin neurons change their response to noradrenaline after sleep deprivation. J Neurosci 25:4127-4130.

Harris AZ, Pettit DL (2008) Recruiting extrasynaptic NMDA receptors augments synaptic signaling. J Neurophysiol 99:524-533.

Hennevin E, Huetz C, Edeline JM (2007) Neural representations during sleep: from sensory processing to memory traces. Neurobiol Learn Mem $87: 416-440$.

Ito I, Sakimura K, Mishina M, Sugiyama H (1996) Age-dependent reduction of hippocampal LTP in mice lacking N-methyl-D-aspartate receptor epsilon 1 subunit. Neurosci Lett 203:69-71.

Kapfhamer D, Valladares O, Sun Y, Nolan PM, Rux JJ, Arnold SE, Veasey SC, Bućan M (2002) Mutations in Rab3a alter circadian period and homeostatic response to sleep loss in the mouse. Nat Genet 32:290-295.

Kim MJ, Dunah AW, Wang YT, Sheng M (2005) Differential roles of NR2Aand NR2B-containing NMDA receptors in Ras-ERK signaling and AMPA receptor trafficking. Neuron 46:745-760.

Kirkwood A, Rioult MC, Bear MF (1996) Experience-dependent modification of synaptic plasticity in visual cortex. Nature 381:526-528.

Kiyama Y, Manabe T, Sakimura K, Kawakami F, Mori H, Mishina M (1998) Increased thresholds for long-term potentiation and contextual learning in mice lacking the NMDA-type glutamate receptor epsilon1 subunit. J Neurosci 18:6704-6712.

Köhr G (2006) NMDA receptor function: subunit composition versus spatial distribution. Cell Tissue Res 326:439-446.

Kopp C, Longordo F, Nicholson JR, Lüthi A (2006) Insufficient sleep reversibly alters bidirectional synaptic plasticity and NMDA receptor function. J Neurosci 26:12456-12465.

Kutsuwada T, Kashiwabuchi N, Mori H, Sakimura K, Kushiya E, Araki K, Meguro H, Masaki H, Kumanishi T, Arakawa M, et al (1992) Molecular diversity of the NMDA receptor channel. Nature 358:36-41.

Lin MT, Luján R, Watanabe M, Adelman JP, Maylie J (2008) SK2 channel plasticity contributes to LTP at Schaffer collateral-CA1 synapses. Nat Neurosci 11:170-177.

Longordo F, Kopp C, Lüthi A (2009) Consequences of sleep deprivation on neurotransmitter receptor expression and function. Eur J Neurosci 29:1810-1819.

Lozovaya NA, Grebenyuk SE, Tsintsadze TSh, Feng B, Monaghan DT, Krishtal OA (2004) Extrasynaptic NR2B and NR2D subunits of NMDA receptors shape 'superslow' afterburst EPSC in rat hippocampus. J Physiol 558:451-463.

Malenka RC, Bear MF (2004) LTP and LTD: an embarrassment of riches. Neuron 44:5-21.

McDermott CM, LaHoste GJ, Chen C, Musto A, Bazan NG, Magee JC (2003) Sleep deprivation causes behavioral, synaptic, and membrane excitability alterations in hippocampal neurons. J Neurosci 23:9687-9695.

McDermott CM, Hardy MN, Bazan NG, Magee JC (2006) Sleep deprivation-induced alterations in excitatory synaptic transmission in the CA1 region of the rat hippocampus. J Physiol 570:553-565.

Migaud M, Charlesworth P, Dempster M, Webster LC, Watabe AM, Makhinson M, He Y, Ramsay MF, Morris RG, Morrison JH, O’Dell TJ, Grant SG (1998)
Enhanced long-term potentiation and impaired learning in mice with mutant postsynaptic density-95 protein. Nature 396:433-439.

Miyamoto H, Hensch TK (2003) Reciprocal interaction of sleep and synaptic plasticity. Mol Interv 3:404-417.

Miyamoto H, Katagiri H, Hensch T (2003) Experience-dependent slowwave sleep development. Nat Neurosci 6:553-554.

Modirrousta M, Mainville L, Jones BE (2007) Dynamic changes in GABAA receptors on basal forebrain cholinergic neurons following sleep deprivation and recovery. BMC Neurosci 8:15.

Monyer H, Burnashev N, Laurie DJ, Sakmann B, Seeburg PH (1994) Developmental and regional expression in the rat brain and functional properties of four NMDA receptors. Neuron 12:529-540.

Philpot BD, Sekhar AK, Shouval HZ, Bear MF (2001) Visual experience and deprivation bidirectionally modify the composition and function of NMDA receptors in visual cortex. Neuron 29:157-169.

Philpot BD, Cho KK, Bear MF (2007) Obligatory role of NR2A for metaplasticity in visual cortex. Neuron 53:495-502.

Popescu G (2005) Mechanism-based targeting of NMDA receptor functions. Cell Mol Life Sci 62:2100-2111.

Popescu G, Robert A, Howe JR, Auerbach A (2004) Reaction mechanism determines NMDA receptor response to repetitive stimulation. Nature 430:790-793.

Quinlan EM, Lebel D, Brosh I, Barkai E (2004) A molecular mechanism for stabilization of learning-induced synaptic modifications. Neuron 41:185-192.

Racca C, Stephenson FA, Streit P, Roberts JD, Somogyi P (2000) NMDA receptor content of synapses in stratum radiatum of the hippocampal CA1 area. J Neurosci 20:2512-2522.

Rumbaugh G, Vicini S (1999) Distinct synaptic and extrasynaptic NMDA receptors in developing cerebellar granule neurons. J Neurosci 19:10603-10610.

Sakimura K, Kutsuwada T, Ito I, Manabe T, Takayama C, Kushiya E, Yagi T, Aizawa S, Inoue Y, Sugiyama H, et al (1995) Reduced hippocampal LTP and spatial learning in mice lacking NMDA receptor epsilon 1 subunit. Nature 373:151-155.

Scimemi A, Fine A, Kullmann DM, Rusakov DA (2004) NR2B-containing receptors mediate cross talk among hippocampal synapses. J Neurosci 24:4767-4777.

Sobczyk A, Scheuss V, Svoboda K (2005) NMDA receptor subunitdependent $\left[\mathrm{Ca}^{2+}\right]$ signaling in individual hippocampal dendritic spines. J Neurosci 25:6037-6046.

Tang YP, Shimizu E, Dube GR, Rampon C, Kerchner GA, Zhuo M, Liu G, Tsien JZ (1999) Genetic enhancement of learning and memory in mice. Nature 401:63-69.

Thomas MJ, Moody TD, Makhinson M, O’Dell TJ (1996) Activitydependent beta-adrenergic modulation of low frequency stimulation induced LTP in the hippocampal CA1 region. Neuron 17:475-482.

Vyazovskiy VV, Cirelli C, Pfister-Genskow M, Faraguna U, Tononi G (2008) Molecular and electrophysiological evidence for net synaptic potentiation in wake and depression in sleep. Nat Neurosci 11:200-208.

Walker MP, Stickgold R (2004) Sleep-dependent learning and memory consolidation. Neuron 44:121-133.

Yashiro K, Philpot BD (2008) Regulation of NMDA receptor subunit expression and its implications for LTD, LTP, and metaplasticity. Neuropharmacology 55:1081-1094.

Yashiro K, Corlew R, Philpot BD (2005) Visual deprivation modifies both presynaptic glutamate release and the composition of perisynaptic/extrasynaptic NMDA receptors in adult visual cortex. J Neurosci 25:11684-11692.

Zeng H, Chattarji S, Barbarosie M, Rondi-Reig L, Philpot BD, Miyakawa T, Bear MF, Tonegawa S (2001) Forebrain-specific calcineurin knockout selectively impairs bidirectional synaptic plasticity and working/episodiclike memory. Cell 107:617-629. 